University of Rhode Island

DigitalCommons@URI

Civil \& Environmental Engineering Faculty

Publications

Civil \& Environmental Engineering

2020

\title{
Dynamics of confined water and its interplay with alkali cations in sodium aluminosilicate hydrate gel: insights from reactive force field molecular dynamics
}

\author{
Gideon A. Lyngdoh \\ University of Rhode Island \\ Rajesh Kumar \\ N. M. Anoop Krishnan \\ Sumanta Das \\ University of Rhode Island, sumanta_das@uri.edu
}

Follow this and additional works at: https://digitalcommons.uri.edu/cve_facpubs

\section{Citation/Publisher Attribution}

G.A. Lyngdoh, R. Kumar, N.M.A. Krishnan, S. Das, Dynamics of Confined Water and its Interplay with Alkali Cations in Sodium Aluminosilicate Hydrate Gel: Insights from Reactive Force Field Molecular Dynamics, Phys. Chem. Chem. Phys. (2020). https://doi.org/10.1039/D0CP04646A

Available at: https://doi.org/10.1039/D0CP04646A

This Article is brought to you for free and open access by the Civil \& Environmental Engineering at DigitalCommons@URI. It has been accepted for inclusion in Civil \& Environmental Engineering Faculty Publications by an authorized administrator of DigitalCommons@URI. For more information, please contact digitalcommonsgroup@uri.edu. 


\title{
Dynamics of Confined Water and its Interplay with Alkali Cations in Sodium Aluminosilicate Hydrate Gel: Insights from Reactive Force Field Molecular Dynamics
}

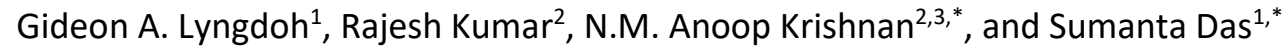 \\ ${ }^{1}$ Department of Civil and Environmental Engineering, University of Rhode Island, Kingston, RI, USA \\ ${ }^{2}$ Department of Civil Engineering, Indian Institute of Technology Delhi, Hauz Khas, New Delhi, 110016, \\ India
}

${ }^{3}$ Department of Materials Science and Engineering, Indian Institute of Technology Delhi, Hauz Khas, New

Delhi, 110016, India

*Corresponding authors: N. M. A. Krishnan (krishnan@iitd.ac.in), S. Das (sumanta das@uri.edu)

Physical Chemistry Chemical Physics, https://doi.org/10.1039/D0CP04646A

\begin{abstract}
This paper presents the dynamics of confined water and its interplay with alkali cations in disordered sodium aluminosilicate hydrate (N-A-S-H) gel using reactive force field molecular dynamics. N-A-S-H gel is the primary binding phase in geopolymers formed via alkaline activation of fly ash. Despite attractive mechanical properties, geopolymers suffer from durability issues, particularly the alkali leaching problem which has motivated this study. Here, the dynamics of confined water and the mobility of alkali cations in $\mathrm{N}-\mathrm{A}-\mathrm{S}-\mathrm{H}$ is evaluated by obtaining the evolution of mean squared displacements and Van Hove correlation function. To evaluate the influence of the composition of N-A-S-H on the water dynamics and diffusion of alkali cations, atomistic structures of $\mathrm{N}-\mathrm{A}-\mathrm{S}-\mathrm{H}$ with Si/Al ratio ranging from 1 to 3 are constructed. It is observed that the diffusion of confined water and sodium is significantly influenced by the Si/Al ratio. The confined water molecules in N-A-S-H exhibit a multistage dynamic behavior where they can be classified as mobile and immobile water molecules. While the mobility of water molecules gets progressively restricted with an increase in Si/Al ratio, the diffusion coefficient of sodium also decreases as the Si/Al ratio increases. The diffusion coefficient of water molecules in the N-A-S-H structure exhibit a lower value than those of the calcium-silicate-hydrate (C-S-H) structure. This is mainly due to the random disordered structure of $\mathrm{N}-\mathrm{A}-\mathrm{S}-\mathrm{H}$ as compared to the layered $\mathrm{C}-\mathrm{S}-\mathrm{H}$ structure. To further evaluate the influence of water content in $\mathrm{N}-\mathrm{A}-\mathrm{S}-\mathrm{H}$, atomistic structures of $\mathrm{N}-\mathrm{A}-\mathrm{S}-\mathrm{H}$ with water contents ranging from $5-20 \%$ are constructed. $Q^{n}$ distribution of the structures indicates significant depolymerization of N-A-S-H structure with increasing water content. Increased conversion of $\mathrm{Si}-\mathrm{O}-\mathrm{Na}$ network to $\mathrm{Si}-\mathrm{O}-\mathrm{H}$ and $\mathrm{Na}-\mathrm{OH}$ components with an increase in water content helps explain the alkali-leaching issue in fly ash-based geopolymers observed macroscopically. Overall, the results in this study can be used as a starting point towards multiscale simulation-based design and development of durable geopolymers.
\end{abstract}

Keywords: geopolymer; sodium aluminosilicate hydrate gel; diffusion; molecular dynamics simulations 


\section{INTRODUCTION}

Geopolymers produced through alkaline activation of aluminosilicate precursor materials (such as Metakaolin, blast furnace slag, or fly ash) have emerged as sustainable alternatives to ordinary portland cement $(\mathrm{OPC})^{1-5}$. Analogous to calcium silicate hydrate (C-S-H) in hardened cement paste, sodium aluminosilicate hydrate (N-A-S-H) gel is the main binding phase in sodium hydroxide $(\mathrm{NaOH})$-activated fly ash-based geopolymers. Geopolymers have been shown to exhibit impressive mechanical performance and better resistance against chlorides/sulfate attacks as compared to OPC ${ }^{6-13}$. Besides, the $\mathrm{CO}_{2}$ emissions have been shown to reduce significantly by $25 \%$ to $40 \%{ }^{9,14-16}$ when compared to OPC binder. Such an enhancement in terms of both reduced carbon footprint and improved mechanical/durability performance makes geopolymers a promising candidate as an environment-friendly alternative binding material to OPC. However, one of the major concerns regarding the large scale use of geopolymers has been the issue of leaching of alkalis, which aids in accelerated deterioration of the material in the long run especially under moist or wet conditions ${ }^{17}$. The presence of excessive residual water in geopolymers is found to de-polymerize the network structure, which indirectly promotes the leaching of alkali ions thereby leading to severe deterioration in mechanical performance of such geopolymer binders ${ }^{18,19}$. Thus, understanding the influence of the dynamics of the confined water on the movement of each alkali cations in N-A-S-H gel is expected to unfold novel pathways towards design of efficient and durable geopolymers.

While the influence of chemical composition ${ }^{20-25}$ and curing conditions ${ }^{24,26,27}$ on the efflorescence behavior of geopolymers have been studied previously using experimental evaluations, fundamental molecular mechanisms responsible for such behavior still remain poorly understood. Toward that end, this paper evaluates the dynamics of water, confined in the nano-pores of the N-A-S-H gel and its interaction with alkali cations using reactive force field $\left(\operatorname{ReaxFF}^{28}\right)$ molecular dynamics simulations so as to obtain fundamental insights on the molecular mechanisms within the N-A-S-H gel responsible for the efflorescence behavior of fly ash-based geopolymers. While fly ash-based geopolymers have been researched extensively ${ }^{1,29,30}$ over the past decades, the molecular structure of $\mathrm{N}-\mathrm{A}-\mathrm{S}-\mathrm{H}$ has recently been proposed ${ }^{31-35}$. Under X-Ray Diffraction (XRD) test and nuclear magnetic resonance (NMR) spectroscopy ${ }^{16,36-44}$, geopolymer gel is shown to exhibit as an amorphous structure opposite to crystalline zeolites structure ${ }^{45}$. In this paper, the molecular structure of N-A-S-H gel is developed by following the general melt-quench approach ${ }^{46,47}$, which is extensively used to obtain amorphous glass from the crystalline structure. The obtained glassy structure is hydrated by performing Grand Canonical Monte Carlo (GCMC) simulation ${ }^{48}$ to obtain the N-A-S-H structure. The inter-atomic interactions are implemented 
by using the Reactive Force field (ReaxFF) ${ }^{28}$. Overall, fundamental insights on the influence of the dissociation of water and its interplay with alkali cations in N-A-S-H gel reported in this paper are expected to foster efficient tuning of the composition and structure formation toward the development of durable geopolymer binders.

\section{SIMULATION METHODOLOGY}

This section provides a brief description of the model construction procedure for the N-A-S-H structure. The structural properties for short and medium-range order are also elucidated. Finally, the method to compute the diffusion coefficient for different cations from MD simulation is detailed, followed by simulation results and discussions.

\subsection{Molecular structure of NAS glass and NASH gel}

In this study, three sodium aluminosilicate (NAS) glasses with Si/Al ratio of 1,2, and 3 are considered whereas the $\mathrm{Na} / \mathrm{Al}$ ratio is kept as 1 . Following the melt-quench procedure ${ }^{46,47}$, the glass is prepared by randomly packing $\mathrm{Si}, \mathrm{Al}, \mathrm{Na}$, and $\mathrm{O}$ species in the simulated box. The system is then heated at $4000 \mathrm{~K}$ for 500 ps each in isothermal-isobaric (NPT) ensemble and canonical (NVT) ensemble using Nose'-Hover thermostat ${ }^{49}$ to make sure that there is a loss of memory with respect to the initial configuration. The simulation is then followed by quenching the prepared structure from $4000 \mathrm{~K}$ to $300 \mathrm{~K}$ with a cooling rate of $1 \mathrm{~K} / \mathrm{ps}$ in NPT ensemble. Such cooling rate has been successfully adopted for preparing other silicate glasses $^{50-52}$. The obtained glass structure is equilibrated in the NPT ensemble for 500 ps followed by the NVT ensemble for 300 ps and another 200 ps for production. In order to hydrate the glass structure, a Grand Canonical Monte Carlo (GCMC) simulation ${ }^{48}$ in the grand canonical ensemble $(\mu V T)$ is applied. In this study, the value for chemical potential $\mu$ is set as $0 \mathrm{eV}$ and the temperature is maintained at $300 \mathrm{~K}$ to provide an unlimited supply of water until saturation. To allow saturation with a stable distribution of water, the simulation is run for one million steps. In this study, the saturated structure is achieved at water content between 16-20 wt\%, which is also observed experimentally in the previous literature (15-20 $\mathrm{wt} \%)^{53}$. The final obtained structure was then equilibrated in NPT to stabilize the temperature at $300 \mathrm{~K}$ and 0 atm pressure for 300 ps and in NVT at $300 \mathrm{~K}$ for another $300 \mathrm{ps}$ and followed by $200 \mathrm{ps}$ for production. The composition of the NAS glasses and its hydrated structures is shown in Table 1. The computed density from MD simulation for $\mathrm{N}-\mathrm{A}-\mathrm{S}-\mathrm{H}$ structures lies in the range from $1.9-2.37 \mathrm{~g} / \mathrm{cm}^{3}$, which is in agreement with the values obtained from experimental observations for sodium-based geopolymers $\left(1.7-2.4 \mathrm{~g} / \mathrm{cm}^{3}\right)^{17,54,55}$. 
Table 1: Chemical composition of the disordered glass and gels with water content and density

\begin{tabular}{|l|l|l|l|l|l|}
\hline Structure & \multicolumn{1}{|c|}{$\begin{array}{c}\mathrm{SiO}_{2} \\
(w t \%)\end{array}$} & $\begin{array}{c}\mathrm{Al}_{2} \mathrm{O}_{3} \\
(w t \%)\end{array}$ & $\begin{array}{c}\mathrm{Na}_{2} \mathrm{O} \\
(w t \%)\end{array}$ & $\begin{array}{l}\text { Water content } \\
(w t \%)\end{array}$ & $\begin{array}{l}\text { Density } \\
\left(\mathrm{g} / \mathrm{cm}^{3}\right)\end{array}$ \\
\hline NAS1 (Si/Al = 1) & 42.30 & 35.89 & 21.82 & - & 2.53 \\
\hline NAS2 (Si/Al = 2) & 59.45 & 25.22 & 15.33 & - & 2.42 \\
\hline NAS3 (Si/Al = 3) & 68.74 & 19.44 & 11.82 & - & 2.24 \\
\hline NASH1 (Si/Al = 1) & 35.46 & 30.09 & 18.29 & 16.17 & 2.37 \\
\hline NASH2 (Si/Al = 2) & 49.37 & 20.94 & 12.73 & 16.95 & 2.11 \\
\hline NASH3 (Si/Al = 3) & 55.44 & 15.41 & 9.37 & 19.78 & 1.99 \\
\hline
\end{tabular}

NASH1, NASH2, and NASH3 in table 1 denote the hydrated structures of NAS1, NAS2, and NAS3 glasses respectively. Figure $1(a)$ and (b) show the representative molecular structure of NAS3 and NASH3 respectively.

(a)

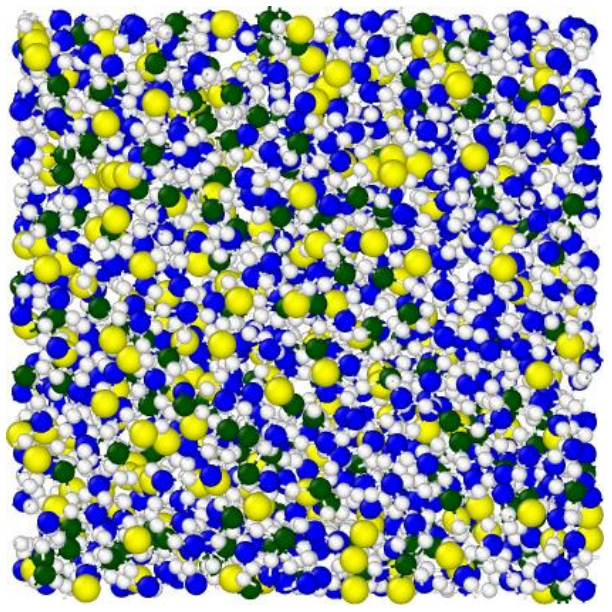

(b)

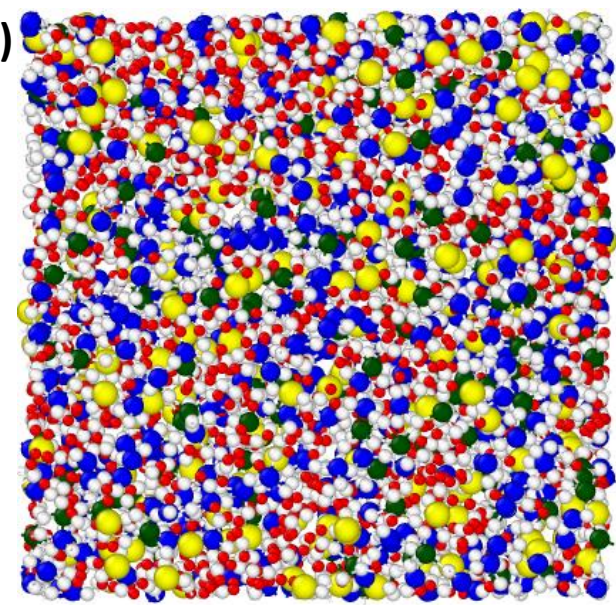

Figure 1: Representative molecular structure of (a) NAS3 glass, and NASH3 structures where Si/Al is equal to 3 (Al: Green, Si: Navy Blue, Na: Yellow, O: White, and H: Red).

Dimensions of N-A-S-H molecular structures, thus obtained, are $25 \AA \times 25 \AA \times 25 \AA$. Throughout the simulation, a reactive force field $\left(\operatorname{ReaxFF}^{56}\right)$ is implemented to generate the NAS and NASH gel structures, which has also been adopted for similar materials ${ }^{34,56}$. All simulations are performed in an open-source software LAMMPS $^{57}$ and Ovito $^{58}$ is used for visualization. The time step taken in the preparation and equilibration of the disordered molecular structure is $0.25 \mathrm{fs}$, and the same timestep is maintained for all the simulations in this paper. In order to simulate the mean square displacement (MSD), the size of the 
NASH structure is adopted as $50 \AA$ x $50 \AA$ x $50 \AA$, which contains approximately 13000 atoms. Any further increase in the box size shows negligible improvements in the results while the computational demand increases significantly. Besides, such size of the simulation box has been shown to provide reliable results to study diffusion using molecular dynamics simulation with negligible finite size effect ${ }^{59}$. A good accuracy has also been achieved in a previous study that evaluates diffusion of species in calcium silicate hydrate (CSH) gel ${ }^{60}$ with a smaller size of the simulation box as compared to the size adopted in this study.

\subsection{Interatomic potential}

In this study, ReaxFF ${ }^{28}$ potential is implemented for atomic interactions in the molecular structures to model the NAS and NASH structures and to study their properties. In the framework of ReaxFF, the total energy of an atomic system ( $\left.E_{\text {system }}\right)$ is dividend in multiple components: ${ }^{61}$

$$
E_{\text {system }}=E_{\text {bond }}+E_{\text {angle }}+E_{\text {torsion }}+E_{\text {vdWaals }}+E_{\text {coulumb }}+E_{\text {under }}+E_{\text {over }}+E_{\text {specific }}
$$

Here $E_{\text {bond }}$ indicates the energy associated with bonds formation between atoms based on interatomic distance. $E_{a n g l e}$ and $E_{\text {torsion }}$ are the angular and torsional energy respectively. The terms $E_{v d W a a l s}$ and $E_{\text {Coulomb }}$ refer to the van der Waals and Coulombic contribution calculated between two pairs, irrespective of their connectivity and bond order. While $E_{\text {under }}$ is the energy penalty for under coordination of atoms that is based on atomic valence rules, $E_{\text {over }}$ indicates the energy penalty for over coordination of atoms. $E_{\text {specific }}$ denotes specific system terms that are adopted for the system of interest such as lone-pair, conjugation, hydrogen binding, and $\mathrm{C}_{2}$ correction ${ }^{61}$. One of the advantages of ReaxFF over other forcefields is that ReaxFF relies on the bond order, which is directly calculated from the instantaneous distances that are updated continuously, and this allows for the creation and dissociation of bonds during simulation, which is also the salient feature of ReaxFF. ReaxFF potential has been successfully implemented in MD simulations toward obtaining efficient atomic structures for a wide variety of materials ${ }^{28,62-64}$. The ReaxFF is adopted from a previous study ${ }^{65}$ that evaluates a similar material system. Please refer to the supplementary material (Section E) for the ReaxFF file used in this study.

\subsection{Structural Characterization}

The short-range order $(<3 \AA)$ of the constructed molecular structures is evaluated using total pair distribution (PDF). The PDF is the ratio of the local density of atoms with respect to the global density of the atoms expressed as a function of distance from an atom. In particular, neutron PDF is given as ${ }^{64,66,67}$ :

$$
g_{N}(r)=\frac{1}{\sum c_{i} c_{j} b_{i} b_{j}} \sum c_{i} c_{j} b_{i} b_{j} g_{i j}(r)
$$


where $c_{i}$ is the fraction of $i$ atoms $(i=\mathrm{Al}, \mathrm{Si}, \mathrm{Na}, \mathrm{O}$ or $\mathrm{H}), b_{i}$ is the neutron scattering length of the species, and $g_{i j}$ are the partial PDFs. To take into consideration the maximal scattering vector $\mathrm{Q}_{\max }$ of the experimental structure factor, the computed $g(r)$ was broadened using the methodology described by Wright et al. ${ }^{68}$ This is achieved by convoluting the component correlation function (such as pdf) with a gaussian function and then adding them together. To avoid extra peak broadening, the interval used in the accumulation of the component of correlation functions must be small as compared to the full width at half maximum height of the experimental resolution function in real space.

To investigate the medium-range order of the constructed structures, structure factors are computed. The partial structure factors are calculated from the Fourier transform of the partial PDF $g_{i j}(r)$ (Equation 2).

$$
S_{i j}(Q)=1+\rho_{0} \int 4 \pi r^{2}\left[g_{i j}(r)-1\right]\left(\frac{\sin \left(Q_{r}\right)}{Q_{r}}\right)\left(\frac{\sin \left(\frac{\pi r}{R}\right)}{\frac{\pi r}{R}}\right) d r
$$

where $Q$ is the scattering vector, $\rho_{0}$ is the average atom number density, and $R$ is the maximum value of the integration in real space, which is set to half of the size of one side of the simulation cell. The total structure factor is calculated as:

$$
S_{N}(Q)=\frac{1}{\left(\sum c_{j} c_{i} b_{j} b_{i}\right)} \sum c_{i} c_{j} b_{i} b_{j} S_{i j}(Q)
$$

where $c_{i}$ and $c_{j}$ are the fractions of atoms and $b_{i}$ and $b_{j}$ are neutron scattering lengths, for elements $i$ and $j$, respectively. The Lorch-type window function is used in this study in order to reduce the effect of the finite cut-off radius in the integration ${ }^{69}$. While the use of such window type has shown to reduce the ripples at low $Q$, this also induces some broadening of the structure factor peaks ${ }^{70}$. Such window function has also been applied successfully to silicate glasses using MD simulation ${ }^{50}$. PDF and structure factors, computed for the constructed molecular structures, are compared against the experimental observations to validate the constructed structures before evaluating the diffusion of water molecules and alkali cations within the N-A-S-H structures.

\subsection{Computation of diffusion coefficient}

The diffusion coefficient is computed from the MSD of the species. MSD is calculated based on the displacement of the species at a given time interval with respect to the initial point. The nature of the variation of MSD with time indicates the modes of the movement (freely diffusive, binding, or active transport). For stable conditions, where the process does not change with time, the MSD is calculated as a time average. The square of the displacement of each atom is expressed as 


$$
S D(t)_{i}=\left(r_{i}(t)-r_{i}(0)\right)^{2}
$$

where $r_{i}(t)$ is the position of atom $i$ at time $t$. Thus, the MSD is calculated by averaging all the SD values over the total number of atoms $(\mathrm{N})$.

$$
M S D(t)_{i}=\frac{1}{N} \sum_{i=0}^{N}\left(r_{i}(t)-r_{i}(0)\right)^{2}
$$

The diffusion coefficient $(D)$ can be calculated from the time evolution of MSD using Einstein's relation ${ }^{33,60}$

$$
D=\lim _{t \rightarrow \infty} \frac{M S D}{6 t}
$$

To illustrate the dynamics properties of each atomic species, the simulation is run for $10 \mathrm{~ns}$ in the NPT ensemble, where the configuration is saved at every 10 ps for respective structures. Such long simulation has also been adopted in the literature to study the diffusion of water in calcium silicate hydrate (CSH) gel $^{60}$.

\section{RESULTS AND DISCUSSION}

This section first demonstrates the short/medium-range order and the partial pair distribution function for the constructed molecular structures to evaluate their realistic nature with respect to experimental observations. Thereafter, the diffusion properties of water molecules and alkali cations are detailed.

\subsection{Structural characterization:}

\subsubsection{Neutron pair distribution function and Neutron structure factor:}

Figure 2 shows the broadened PDFs obtained using the methodology explained in section 2.3 for N-A-S-H structures with different Si/Al composition. The initial peak at $1.0 \AA \AA$ corresponds to the D-O interaction, where $D$ refers to deuterium, where heavy water is used in order to prepare the geopolymer binder ${ }^{38,71}$. The second peak corresponds to a combination of $\mathrm{Si}-\mathrm{O}$ and $\mathrm{Al}-\mathrm{O}$ interactions. The Si-O bond length predicted by ReaxFF is $1.62 \AA$, which corresponds very well to the $\mathrm{Si}-\mathrm{O}$ bond length of Si tetrahedra. For the case of $\mathrm{Al}-\mathrm{O}$, the peak is less clear as they arise from the superimposition of different coordination number $(\mathrm{CN})$ of $\mathrm{Al}(\mathrm{CN}=4$, or 5$)$. The other peak at $2.6 \AA$ corresponds to the $\mathrm{O}-\mathrm{O}$ interactions. All these peaks (in the simulated PDFs) for the constructed N-A-S-H structures are in excellent agreement with

experimental data available in the literature ${ }^{38,71}$ signifying the viability of the constructed structures in terms of short-range order. It is to be noted that in the experimental studies available in the literature ${ }^{38,71}$, 
the N-A-S-H gel was prepared by activating pure metakaolin with deuterated sodium silicate solution with molar ratio $\mathrm{SiO}_{2} / \mathrm{Na}_{2} \mathrm{O}$ equal to 2 . The samples were cured at ambient temperature for 90 days. To quantify the agreement between the experimental and simulated correlation functions, the Wright factor is computed $^{68}$. The Wright factor is expressed $a s^{68}$ :

$$
\mathcal{R}_{\mathcal{H}}=\left[\frac{\sum_{i=1}^{n}\left(g\left(r_{i}\right)-g_{\text {exp }}\left(r_{i}\right)\right)^{2}}{\sum_{i=1}^{n}\left(g_{\text {exp }}\left(r_{i}\right)\right)^{2}}\right]
$$

where $g_{\text {exp }}\left(r_{i}\right)$ is the experimental PDF. These factors are calculated over the range from $1 \AA$ to $8 \AA$ and the computed $\mathcal{R}_{\mathcal{H}}$ for NASH1, NASH2, and NASH3 are $9.5 \%, 9.18 \%$, and $9.75 \%$, respectively. Since the value of $\mathcal{R}_{\mathcal{H}}$ below $10 \%$ can be considered as a good agreement ${ }^{50}$, it can be inferred that constructed NASH structures represent realistic short-range order.
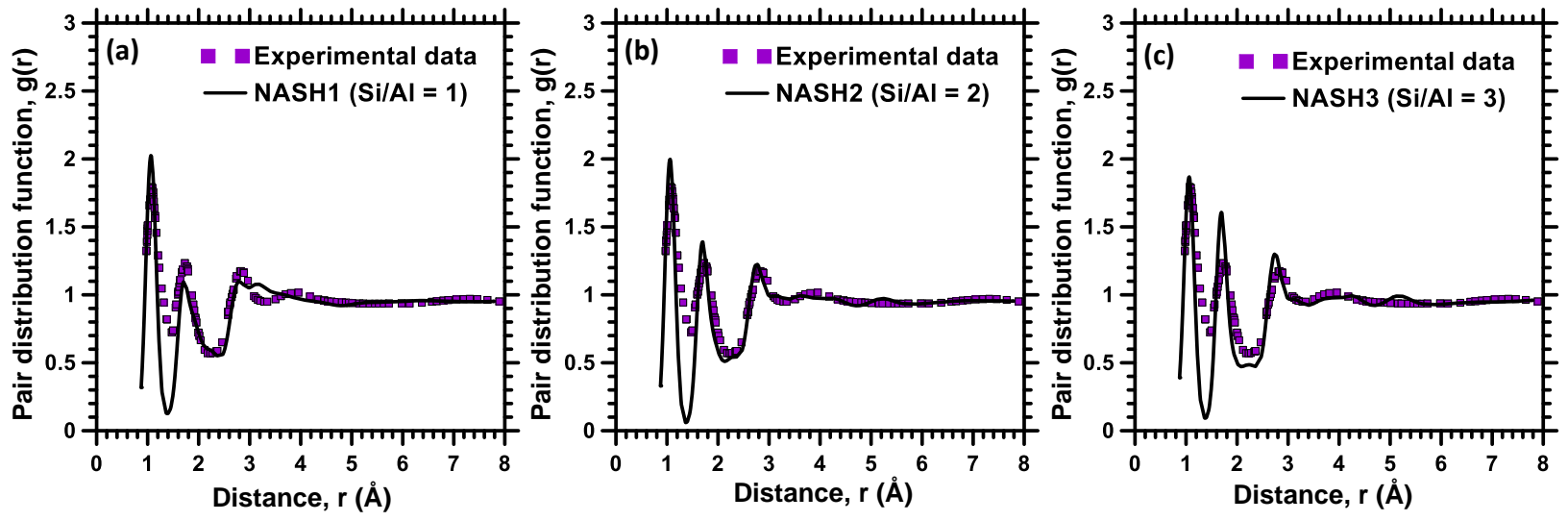

Figure 2: Pair distribution function of (a) NASH1, (2) NASH2, and (c) NASH3, compared with the experimental data ${ }^{71}$.

To analyze the characteristics of the constructed N-A-S-H structures in the medium-range order, the neutron structure factors for the constructed N-A-S-H structures are plotted along with the experimental data $^{38,71}$, as shown in Figure 3. It is evident that the structure factor for NASH (except Si/Al equal to 1) contains four distinct peaks, the position of which correlates very well with the experimental observations ${ }^{38,71}$. However, the first sharp diffraction peak (FSDP) of NASH1 is shifted to a higher $\mathrm{Q}$. This can be attributed to the high content of network modifiers which tends to rupture the covalent network connectivity as well as introduce non-bridging oxygen $(\mathrm{NBO})^{70}$. 


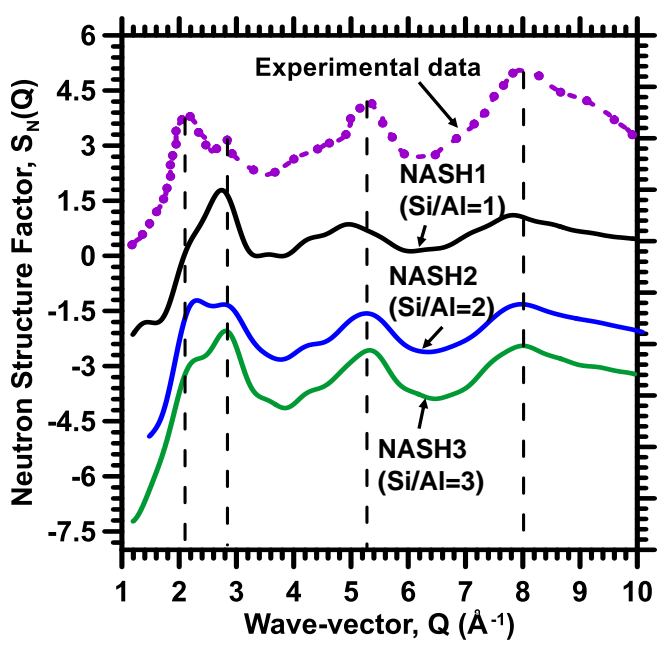

Figure 3: Structure factor of NASH1, NASH2, and NASH3, compared with the experimental data ${ }^{38,71}$.

\subsubsection{Partial pair distribution function}

The local structure of the N-A-S-H gel with different Si/Al composition is investigated in this section by computing the partial pair distribution function (PDF). The symbol $\mathrm{O}$ is used to represent the structural oxygen connected to the ring structure, whereas Ow represents the oxygen in water. Such symbols are used consistently hereafter to differentiate oxygen connected to the ring structure from oxygen in water. In this study, the discussion solely focuses on the interactions of water and alkali species such as $\mathrm{Na}-\mathrm{O}$, $\mathrm{Na}-\mathrm{Ow}, \mathrm{O}-\mathrm{O}, \mathrm{O}-\mathrm{Ow}, \mathrm{Ow}-\mathrm{Ow}, \mathrm{O}-\mathrm{H}$, and $\mathrm{Ow}-\mathrm{H}$. Such evaluations on the interactions between water and alkali species help explain the diffusion behavior of different species, detailed later in this paper. Figure 4(a) shows the partial PDF for $\mathrm{Na}-\mathrm{O}$ interaction in NASH with varying Si/Al ratio.

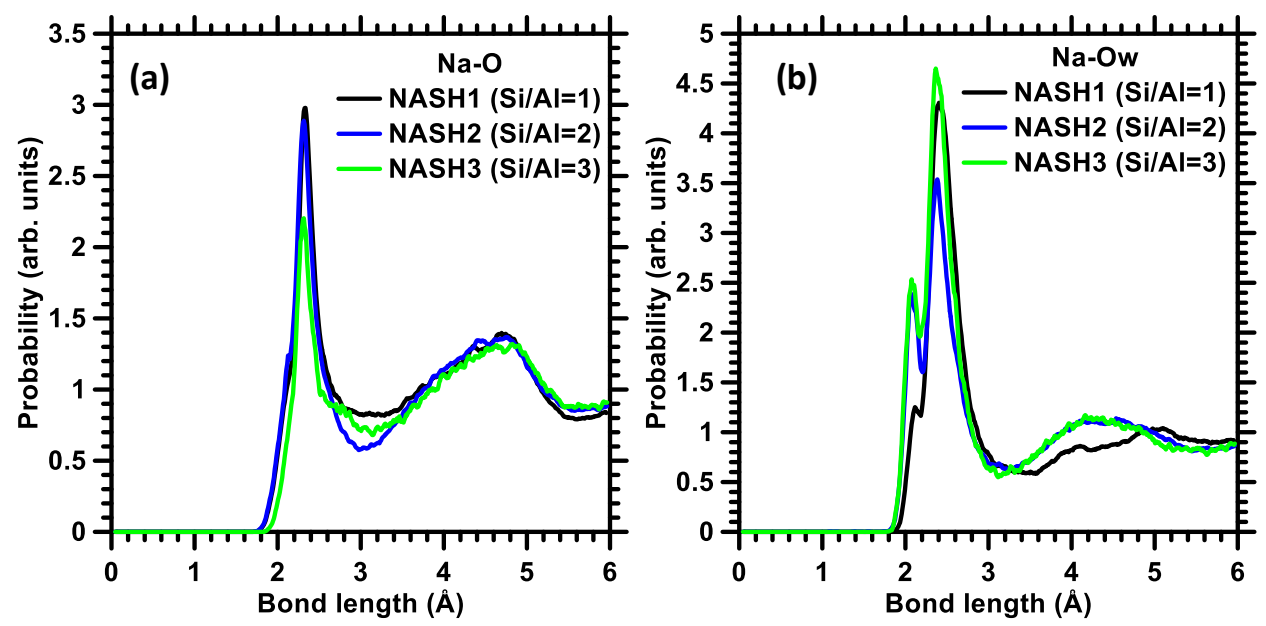

Figure 4: Partial PDF of (a) Na-O, and (b) Na-Ow interactions for NASH1, NASH2, and NASH3. 
From Figure 4(a), two peaks are observed. The first peak at 2.30-2.35 $\mathrm{A}$ corresponds to the interaction of $\mathrm{Na}$ with non-bridging oxygen (NBO), which is also observed both numerically and experimentally $35,72-75$. This indicates the ability of ReaxFF to mimic the experimentally observed Na-O interaction. Figure 4(b) shows the interaction of $\mathrm{Na}$ with water in the three N-A-S-H structures. Here two peaks are observed between 2-2.6 $\AA$. The presence of such a dual peak can be explained from the nature of $\mathrm{Na}$ around the vicinity of water molecules ${ }^{72}$, where the coordination of Na shows variation between 1 to $6^{72}$. The average coordination of $\mathrm{Na}^{+}$with $\mathrm{Ow}$ and $\mathrm{O}$ is found to be between 4.5-5.7 which is in line with the experimentally observed values in the range 4.3-6.2 $\AA^{72-75}$. This shows the consistency of the MD simulations with the experimental observations.

Figure 5(a) shows the partial PDF of tetrahedral oxygen in N-A-S-H with varying Si/Al composition. The first peak 2.73-2.75 $\AA$ is present in all the structures irrespective of $\mathrm{Si} / \mathrm{Al}$ composition and it corresponds to the $\mathrm{O}-\mathrm{O}$ bond $^{35}$. Such results suggest that the $\mathrm{O}-\mathrm{O}$ bond belonging to the ring structure is stable irrespective of the Si/Al content. Figure $5(\mathrm{~b})$ shows the interaction of O-Ow where three distinct peaks are observed $(2.75 \AA$, $3.3 \AA$, and $5.3 \AA$ ). While the first peak at $2.75 \AA$ indicates interaction of $\mathrm{O}$ with the first neighboring atom (first coordination shell between oxygen atoms) in water (Ow), the third peak at $5.3 \AA$ corresponds to second neighbor interactions. The first peak at $2.75 \AA$ is also present in the case of $\mathrm{O}-\mathrm{O}$ and $\mathrm{Ow}-\mathrm{Ow}$ bonds, as shown in Figure 5, and previous observations ${ }^{76-79}$. The second peak observed at $3.3 \AA$ is due to local interaction between the $\mathrm{O}$ and Ow present in the hydrated N-A-S-H structure. The second peak at $3.3 \AA$ is observed in all the N-A-S-H structures. Similar observations are shown for hydrated disordered aluminosilicates in the literature ${ }^{76}$.
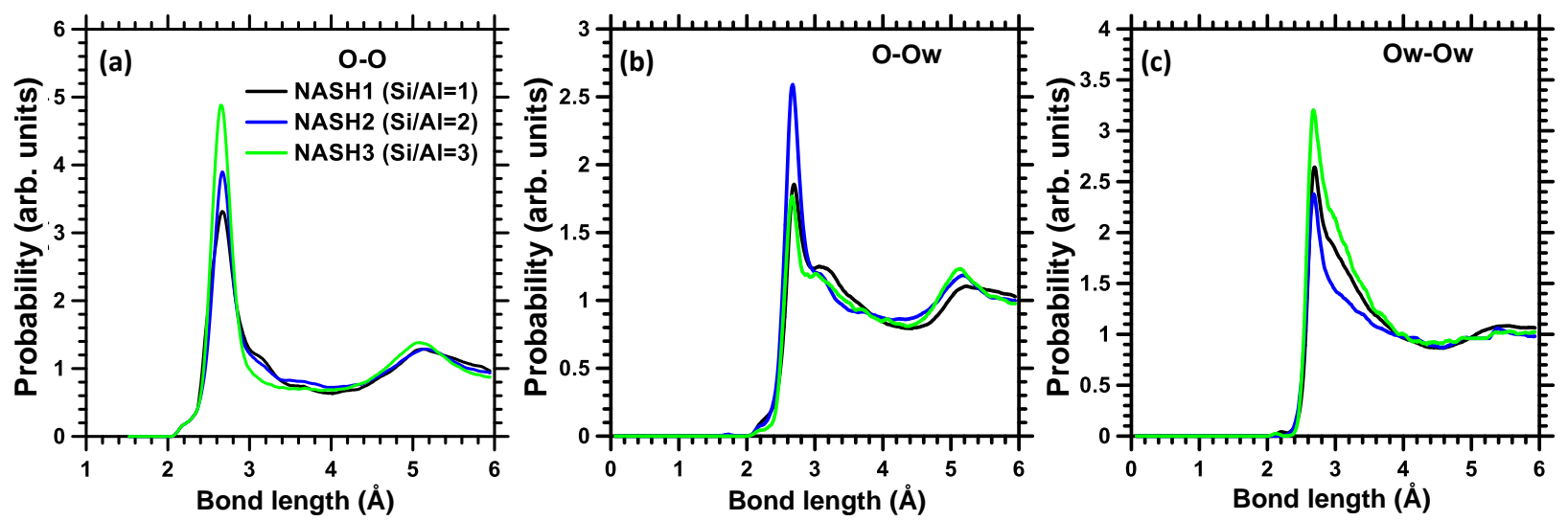

Figure 5: Partial PDF of (a) O-O, (b) O-Ow, and (c) Ow-Ow interactions where $\mathrm{O}$ represents oxygen connected to polyhedral structure and Ow represents oxygen in water for NASH1, NASH2, and NASH3 
Figure 5(c) shows the partial PDF of Ow-Ow interaction in N-A-S-H. The first peak at 2.76 $\AA$ corresponds to the first coordination shell between oxygen atoms in water $(\mathrm{Ow})$. A similar observation is also observed for the case of bulk water at $2.76 \AA^{80}$. In the case of bulk water, the second neighbor interactions are observed at $4.5 \AA^{81}$. However, in N-A-S-H structures, such interactions are not prevalent due to the confined nature of water molecules ${ }^{76}$. These water molecules, when present in the confined space in the glass structure, exhibit anomalous characteristics, which is also observed in the case of calcium silicate hydrate $(\mathrm{CSH})^{82}$.

Figure 6(a) and (b) show the partial PDF for the $\mathrm{O}-\mathrm{H}$, and $\mathrm{O} \mathrm{w}-\mathrm{H}$ interactions respectively. In order to get insight into the behavior of water in the disordered structure, a bulk water system is simulated using the same ReaxFF. Note that a density of approximately $0.94 \mathrm{~g} / \mathrm{cm}^{3}$ is obtained for bulk water using this potential, which is consistent with the value reported in the literature ${ }^{82-84}$. Both $\mathrm{O}-\mathrm{H}$ and $\mathrm{Ow}-\mathrm{H}$ bonds do not show any significant change in bond lengths irrespective of different Si/Al compositions. In the case of Ow-H interaction, it is observed that the behavior of the bonds for gel structure is similar to that of bulk water. Ow-H interaction in bulk water is consistent with the behavior reported in the literature ${ }^{80,85}$.

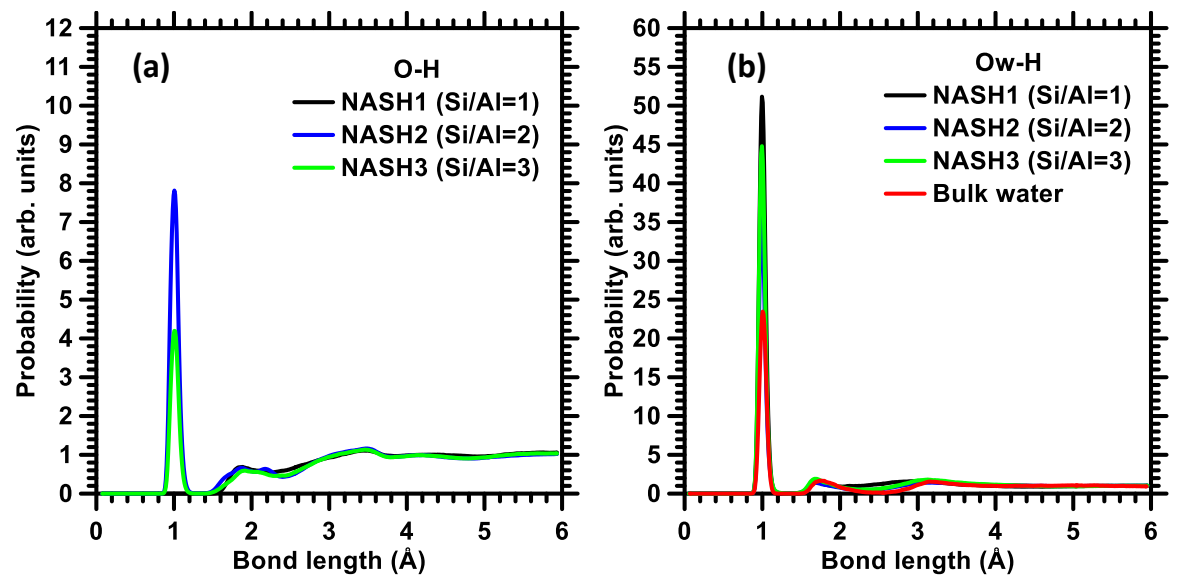

Figure 6: Partial PDF of (a) $\mathrm{O}-\mathrm{H}$, and (b) Ow-H (hydroxyl) where Ow (represent oxygen in water), and $\mathrm{H}$ (represent hydrogen associated with water) for NASH1, NASH2, and NASH3. For Ow-H, a partial PDF from bulk water is also plotted.

\subsection{Diffusion of water molecules and alkali cations in N-A-S-H structure}

While the previous section evaluated the structural attributes of N-A-S-H and the influence of composition on the resulting structural characteristics, this section presents the diffusion behavior of water molecules and alkali cations in the confined water of N-A-S-H structures. The dynamics of different species in the confined water is evaluated by computing the MSD. 


\subsubsection{Dynamics of confined water molecules in N-A-S-H structure}

Figure 7 shows the evolution of MSD of water molecules confined in the N-A-S-H (representative NASH2 structure) structure where four stages, namely ballistic, caged, transition, and diffusive regimes, are clearly observed. Such stages have been reported in the literature for water diffusion in both layered and disordered structures ${ }^{31}$. Region A ( $\left.t \leq 60 \mathrm{ps}\right)$ corresponds to the ballistic regime $\left.\left(<r^{2}(t)\right\rangle \propto t^{2}\right)$ where non-linear increase in MSD is observed with increase in time. In the region B, a plateau region is observed till 200 ps. This region represents the cage effect where water molecules try to escape the polyhedral network formed by the network former species. The region $\mathrm{C}$ represents the transition regime where the water molecules tend to escape the ring network formed by the network former species. In this transition regime, the motion of water molecules can be interpreted as diffusion with low exponent $\left(<r^{2}(t)\right\rangle \propto$ $t^{a}$, where $\left.a<1\right)$. Lastly, the stage $\mathrm{D}$ represents the linear diffusion regime $\left(<r^{2}(t)>\propto t\right)$ after 2 ns.

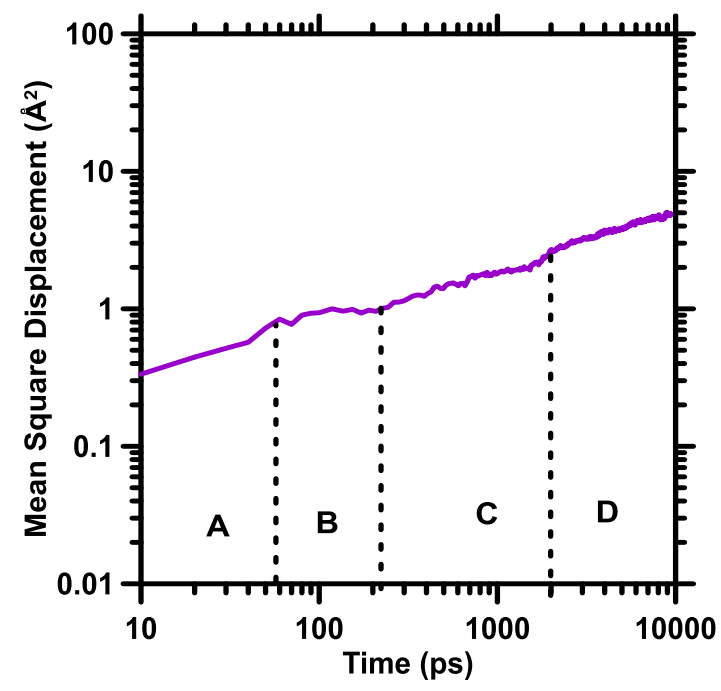

Figure 7: Regions in MSD of water molecules in NASH2 (Si/AL equal to 2).

\subsubsection{Diffusion of atomic species in the confined water of $\mathrm{N}-\mathrm{A}-\mathrm{S}-\mathrm{H}$}

This section evaluates the evolution of MSD of different species in the confined water of N-A-S-H. Figure 8(a) shows the MSD of Al with respect to time. It is observed that the values of MSD of Al atoms in glass is relatively lower compared with those of hydrated structures. As indicated in the previous study ${ }^{34}$, water molecules present in the glass induced stretching of Al-O bonds. Similar trends are also observed for $\mathrm{Si}$, as shown in Figure $8(\mathrm{~b})$. This shows that $\mathrm{Si}$ and $\mathrm{Al}$ atoms in the polyhedral network exhibit similar nature irrespective of the $\mathrm{Si} / \mathrm{Al}$ composition. Their minimal movements indicate that the network connectivity is intact. Figure 8(c) exhibits the MSD of sodium atoms with respect to time. It is observed that the mobility 
of $\mathrm{Na}$ is comparatively higher than those of $\mathrm{Si}$ and $\mathrm{Al}$. As indicated in the literature ${ }^{34}$, the diffusion energy barrier in the NAS glass is in the order of $\mathrm{Si}>\mathrm{Al}>\mathrm{O}>\mathrm{Na}$, which shows that $\mathrm{Si}$ and $\mathrm{Al}$ are more stable than $\mathrm{Na}$. Thus, it is expected that $\mathrm{Na}$ ions can exhibit higher mobility ${ }^{72}$. In addition, the mobility of Si and Al atoms are restricted due to the polyhedral network formed by Si-O-Al bonds. Another observation is that the $\mathrm{Na}$ ions show significantly higher mobility in wet conditions (N-A-S-H structures) when compared to dry conditions (NAS glass), which explains the issue of leaching of $\mathrm{Na}$ from N-A-S-H that has been shown to affect the durability of fly ash-based geopolymers ${ }^{34,72}$. Figure $8(d)$ represents the MSD of oxygen (O) connected to the polyhedral structure. Such oxygen atoms are expected to show less mobility in the dry environment due to their connection to the network structure. However, in a wet environment, dissociation of water leads to the generation of protons (or hydrogen) that tend to form bonds with system oxygen atoms resulting in depolymerization of the structure. This leads to an increase in mobility of the system oxygen in wet conditions compared to dry conditions. The MSD values of O for NAS glass is consistent with the values reported in the literature ${ }^{72}$.
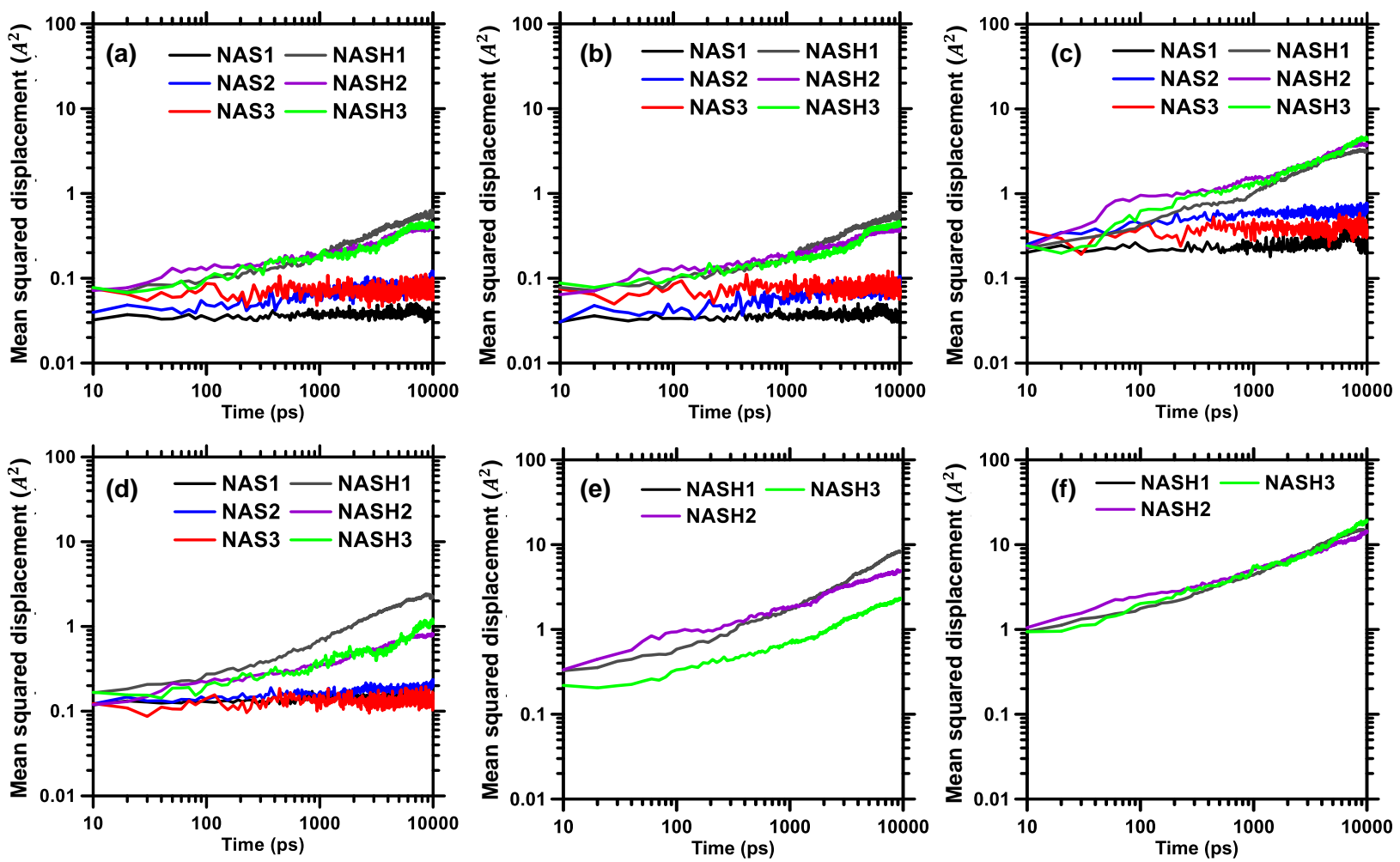

Figure 8: MSD of (a) Al, (b) Si, (c) Na, (d) O, (e) Ow, and (f) $\mathrm{H}$ atoms for NAS glass, N-A-S-H gel with time evolution of $10 \mathrm{~ns}$, respectively.

Figure 8(e) represents the MSD of oxygen in water (Ow). It is observed that such oxygen $(\mathrm{Ow})$ atoms exhibit comparatively higher mobility than the structural oxygen (0), which can be attributed to the 
network restraint formed by network former (Si-O-Al). It is also observed that the MSD values of Ow decrease with an increase in the Si/Al ratio. In order to gain more insight on this behavior, the number of $\mathrm{Si}-[\mathrm{O}, \mathrm{OW}]-\mathrm{H}$ interaction is evaluated for varying Si/Al ratio. It is clearly observed that as the Si/Al ratio increases the percentage of $\mathrm{Si}-[\mathrm{O}, \mathrm{OW}]-\mathrm{H}$ interactions increases (please refer to Section $\mathrm{A}$ of the supplementary document for more information). As the Si content (which is a network former) increases more network connectivity is achieved in the system and this in turn restricts the water to diffuse easily. Also, it is observed from ring size distribution (which is explained later in this paper) the presence of smaller ring size becomes more prevalent with an increase in Si/Al ratio. This further restricts the movement of sodium ion and water molecules in the structure. Figure 8(f) shows the MSD of hydrogen ions (or proton) with respect to time for different Si/Al composition. Hydrogen atoms show significantly higher mobility as compared to all other species in N-A-S-H due to its smaller size, which promotes relatively easier movement of hydrogen atoms. Note that the MSD values for hydrogen atoms, shown in Figure $8(f)$ are consistent with the ones in a study of hydrated silicate glass using ReaxFF potential ${ }^{72}$ which is parameterized for $\mathrm{Na}-\mathrm{Si}-\mathrm{O}-\mathrm{H}$.

To further characterize the nature of water molecules, present in N-A-S-H, this study classifies the water molecules based on their relative mobility as immobile and mobile water molecules. Figure 9(a) shows the MSD of representative individual water molecules in NASH3 ( $\mathrm{Si} / \mathrm{Al}=3$ ) with time. As can be seen from the figure, there is a clear difference in MSD between the mobile water and immobile water. While the MSD for immobile water is less than $2 \AA$, the MSD for mobile water is larger. Thus, threshold RMSD for water molecules is approximately $1.414 \AA$ beyond which the water molecules start hopping. This threshold RMSD corresponds well with the typical cage radius. Another parameter that can be used to classify the mobility of water molecules is based on the slope from MSD, where it can be seen that the slope of immobile water molecules is close to zero (till $1 \mathrm{~ns}$ ) and more than zero for mobile water molecules. Figure 9(b), (c) and (d) show the trajectories of a single sodium ion, immobile water, and mobile water respectively at $300 \mathrm{~K}$. While the mobile water molecule is able to hop to another site (as in this case minimum of two sites), the immobile water molecule vibrates around one site which explains the lower MSD value for immobile water molecules. It is observed that for sodium ions, two separate modes associated with the vibration at two fixed sites are observed. A similar finding is also noted in silicate glass $^{72}$. 

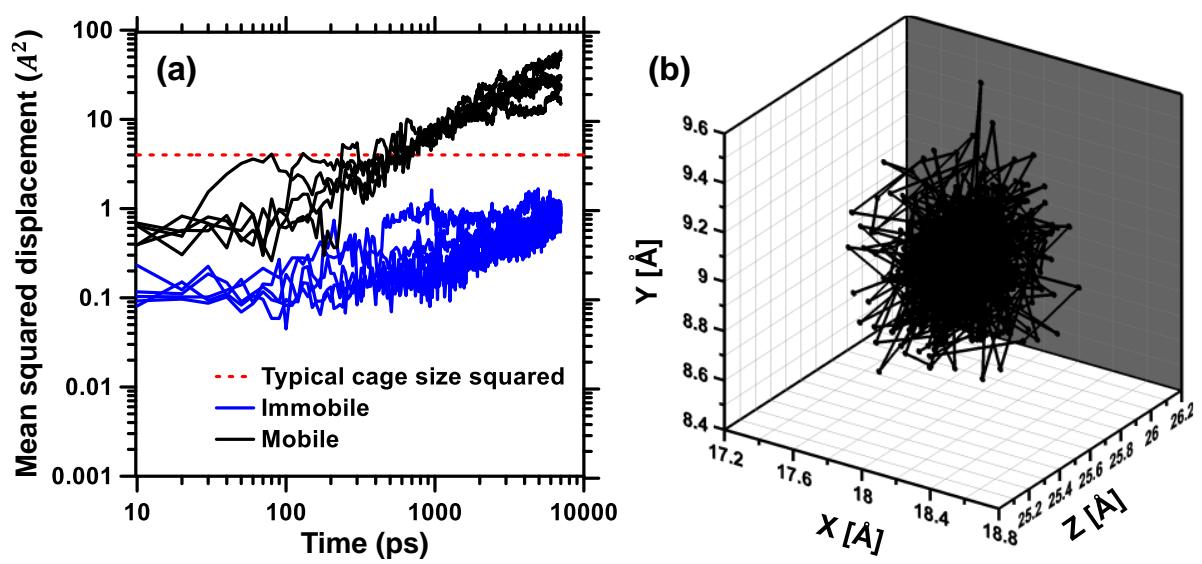

(c)

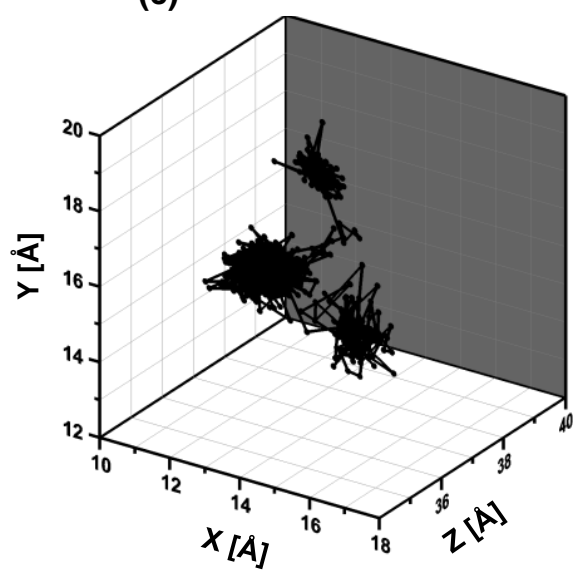

(d)

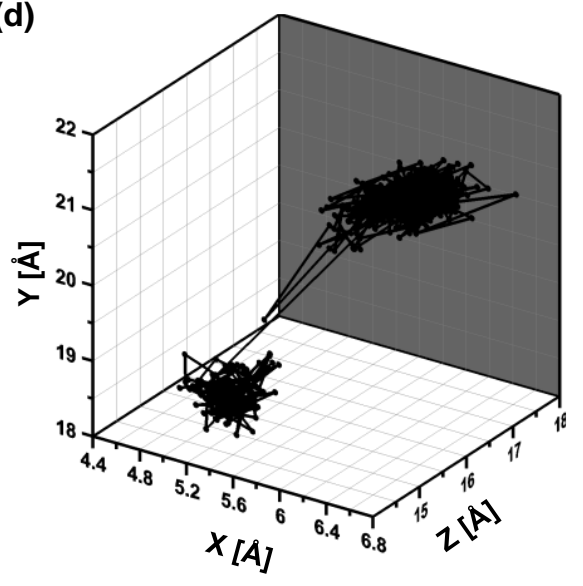

Figure 9: (a) Representative plot of mean squared displacement (MSD) behavior of water molecules as a function of time, (b) trajectory of a representative immobile water molecule, (c) trajectory of a representative mobile water molecule, and (d) trajectory of a representative sodium ion for NASH with $\mathrm{Si} / \mathrm{Al}=3$.

\subsubsection{Diffusion coefficient of sodium and water molecules}

While the previous section showed the evolution of mobility of water molecules and alkali cations in N-A$\mathrm{S}-\mathrm{H}$, this section quantifies the diffusion coefficient of sodium and confined water molecules based on Einstein's equation. The diffusion coefficient is computed in the range from 2 ns to 8 ns where a linear variation of MSD with time holds true with $R^{2}$ values lying between $0.95-0.98$. The linear fitting plots with $R^{2}$ values are provided in section B of the supplementary document. Figure 10(a) shows the computed diffusion coefficient of sodium ion for three different compositions. It is observed that as the content of network former (Si atoms) increases, the diffusivity of sodium decreases. This indicates that the structural role of sodium is composition-dependent, where sodium ion is more mobile when acts as a charge compensator to neutralize the network former (Al) than when it acts as a creator of NBOs on tetrahedrally 
coordinated silicon and aluminum. This relative increase in the diffusion coefficient of sodium ion when acts as a charge compensator indicates that the sodium ions do not form the rigid part of the network ${ }^{86}$. Whereas for the case of low content of $\mathrm{Al}_{2} \mathrm{O}_{3}$, some sodium ions get associated with $\mathrm{Si}-\mathrm{O}$, and these sodium ions are less mobile. Such observation is also illustrated in the literature for silicate glass ${ }^{86}$. This decreasing behavior can also be correlated with the rings structure in N-A-S-H, which investigates the intermediate-range order of molecular structure.
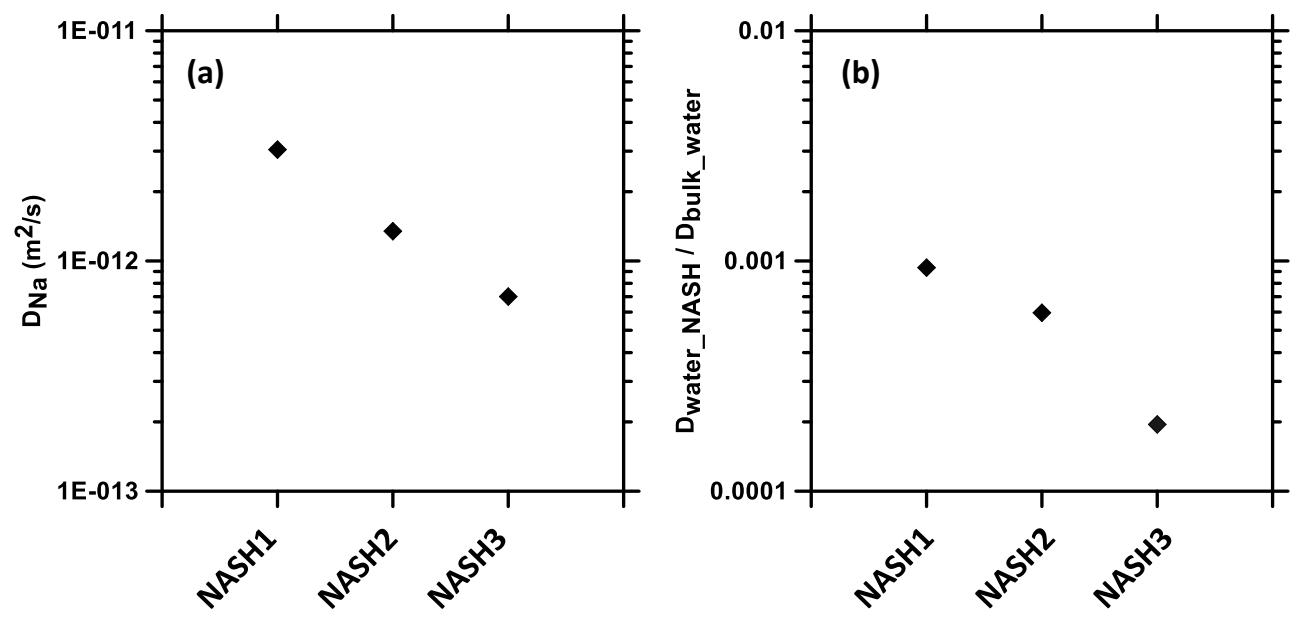

Figure 10: (a) Diffusion coefficient of sodium, and (b) ratio of diffusion of water in N-A-S-H with respect to the bulk water system.

The ring size distribution of each system is computed by implementing the RINGS package ${ }^{87}$. Here, the ring size is defined in terms of the number of $\mathrm{Si}$ and $\mathrm{Al}$ atoms (i.e., on the basis of Si-O-Al connection and ignoring the $\mathrm{Al}-\mathrm{Al}$ or $\mathrm{Si}-\mathrm{Si}$ as part of the ring), and the maximum number ring size of 20 is adopted where good convergence is obtained for the ring size distribution.
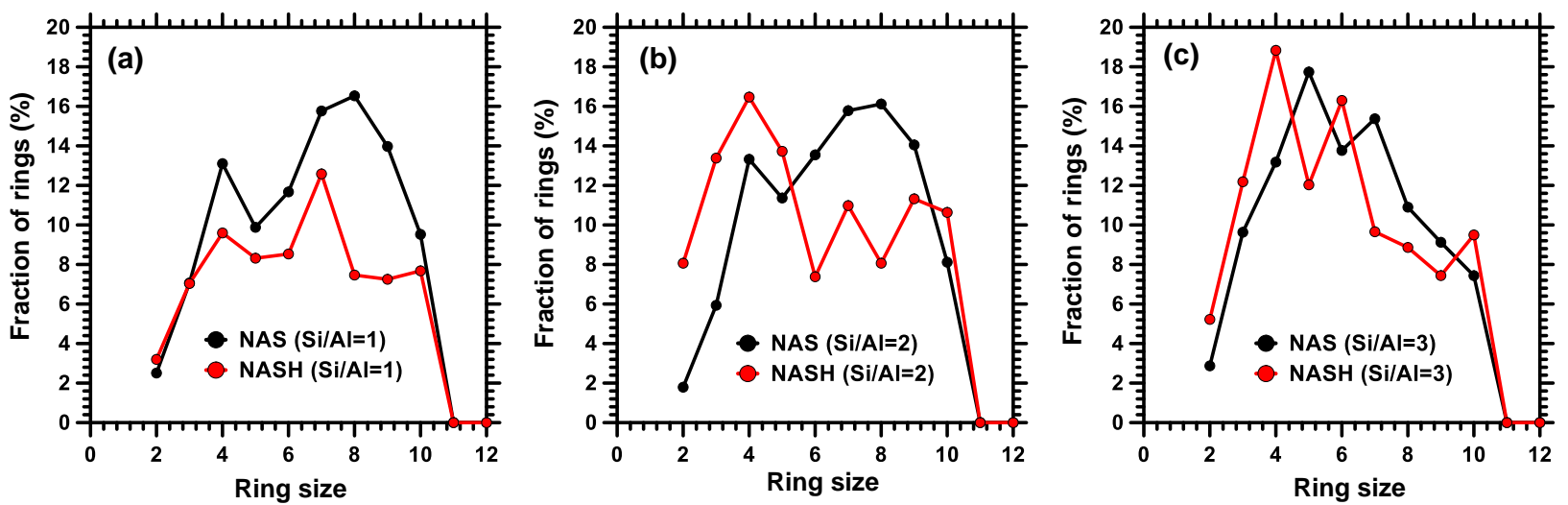

Figure 11: Ring size distribution in N-A-S-H structure with (a) $\mathrm{Si} / \mathrm{Al}=1$, (b) $\mathrm{Si} / \mathrm{Al}=2$, and (c) $\mathrm{Si} / \mathrm{Al}=3$ where the ring size is defined in terms of $\mathrm{Si} / \mathrm{Al}$ atoms belonging to the ring. 
Figure 11 shows the comparison of ring size distribution for glass structure (un-hydrated structure) and $\mathrm{N}-\mathrm{A}-\mathrm{S}-\mathrm{H}$ (hydrated structure) for three different compositions. From the plot, it is observed that the fraction of small ring size (2-4 size rings) increases with an increase in Si/Al ratio which explains the decrease in mobility of sodium ions with increasing Si/ Al ratio. For a direct validation of the obtained diffusion coefficient of $\mathrm{Na}$, no experimental data is available so far, to the best of our knowledge. The only available data in the literature ${ }^{88}$ regarding this deal with the diffusion of $\mathrm{Na}$ in unhardened geopolymer paste with initial water content of $25-35 \%$. Under such early-age (unhardened) condition, diffusion coefficient values of sodium in the range of $4-8 \times 10^{-12} \mathrm{~m}^{2} / \mathrm{s}$ have been reported, which is of the same order as the values obtained from MD simulation especially for NASH with Si/Al equal to 1. Figure 10(b) shows the ratio of the diffusion coefficient of water molecules in the disordered structure with respect to the diffusion coefficient of water bulk system $\left(D_{\text {bulk system }}=3.44 \times 10^{-9} \mathrm{~m}^{2} / \mathrm{s}\right)$. It is clearly visible that the diffusion coefficient decreases with an increase in the Si/Al ratio. Such behavior can be attributed to (i) increasing tendency of the dissociated water to form silanol (Si-O-H) group with Si-O network which restricts the mobility of water molecules in the structure (please refer to Table 1 in the section A of the supplementary document), and (ii) the formation of smaller rings with increasing Si/Al ratio (please refer to Figure 11) which further restricts the water molecules to diffuse easily. For more details on the influence of the $\mathrm{Si} / \mathrm{Al}$ ratio on the oxygen speciation in $\mathrm{N}-\mathrm{A}-\mathrm{S}-\mathrm{H}$ please refer to Section $\mathrm{A}$ of the supplementary document. This highlights the effect of substrate composition on the diffusion of water molecules in the ultra-confined spaces. Nevertheless, the computed ratios of the diffusion coefficient of water molecules in the disordered N-A-S-H structure with respect to the diffusion coefficient of water bulk system are significantly lower than those reported for C-S-H structure ${ }^{60,76}$. This signifies that part of the mobile water molecules in the disordered N-A-S-H structure diffuses with slow dynamics. This can be attributed to the disordered structure of N-A-S-H with random distribution of water molecules whereas $\mathrm{C}-\mathrm{S}-\mathrm{H}$ is a layered structure where most of the water molecules are distributed in the interlayer spaces. Such disordered random distribution of water in the cavity regions around the polyhedral network formed by aluminosilicate skeleton in $\mathrm{N}-\mathrm{A}-\mathrm{S}-\mathrm{H}$ prevents its mobility when compared to $\mathrm{C}-\mathrm{S}-\mathrm{H}$.

\subsubsection{Evaluation of diffusion behavior of sodium and water molecules using Van Hove correlation} function

To further evaluate the dynamic properties of sodium ions and water molecules in N-A-S-H gel, the selfpart of Van Hove space-time correlation function $(H(r, t))$ is computed. This function is expressed as 


$$
H(r, t)=\frac{1}{N} \sum_{i}^{N}<\delta\left(r-\left|r_{i}(t+\tau)-r_{i}(\tau)\right|\right)>
$$

where the term $r_{i}$ denotes the coordinate of oxygen atom $i$ in water (or sodium atom), $\delta$ denotes the Kronecker function, and the term $\tau$ represents time origin. The self-part of Van Hove correlation function $H(r, t)$ yields the probability that a particle originally at $(t=0)$ and $(r=0)$ has moved a distance $r$ in time $t^{89}$. Figure 12(a) shows the $H(r, t)$ at different time scales for sodium ions for a representative N-A-S-H structure with $\mathrm{Si} / \mathrm{Al}$ equal to 3 . It is observed that majority of the sodium atoms oscillates in a confined space (high probability lies in the range below $r$ equal to $2 \AA$ ) initially ( $t \approx 0.01 n s$ ). However, beyond $0.01 \mathrm{~ns}$, peaks start appearing towards the right and this indicates the sodium ions start hopping at different sites. While in the current study the effect of pressure and temperature is neglected the dynamical behavior of sodium cation in the magma is observed to be sensitive to density and temperature using MD simulation as reported in the study by Bauchy et al. ${ }^{89}$ Moreover, the cation diffusion in real scenarios are very sensitive ${ }^{90}$ to dissolved components such as water or carbon dioxide.

Figure 12(b) shows the $H(r, t)$ at different time scales for water molecules. From Figure 12(b), at short interval $(t \approx 0.01 n s)$ water molecules are still in the cage. However, at a longer time scale $(t>0.1 n s)$, some water molecules start escaping the cage and start traveling as far as $3 \AA$ (this is the average $r$ between 2-4 $\AA$ where the second peak is prevalent).
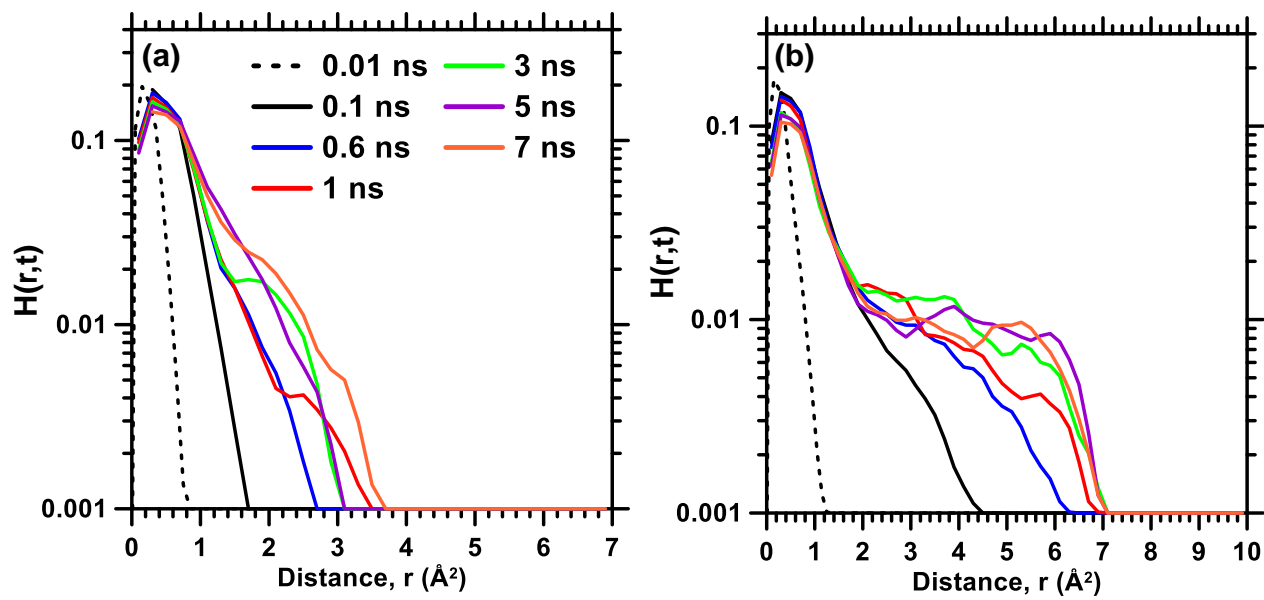

Figure 12: Self part Van Hove function for (a) sodium at different time intervals, (b) water molecules at different times

Beyond $0.1 \mathrm{~ns}$, the multiple peaks start appearing at an average distance of $3 \AA$ and $6 \AA$. While the value $3 \AA$ can be considered as the average jump length in N-A-S-H structure which is at the first hopping site, the other peak at $6 \AA$ can be considered as the second hopping site. These values correspond well with 
the trajectory of the mobile water molecule shown in Figure 9(c). It is noted that the average jump length of bulk water molecules at room temperature is approximately $0.9 \AA^{91}$, whereas the average jump length in supercooled water at $253 \mathrm{~K}$ is roughly $2.4 \AA^{92}$. This suggests that water molecules in confined space in random N-A-S-H structure behaves like a supercooled liquid. Similar observations are reported in the case of $\mathrm{C}-\mathrm{S}-\mathrm{H}^{60}$.

The influence of the Si/Al ratio on the heterogeneity in confined water dynamics in the $\mathrm{N}-\mathrm{A}-\mathrm{S}-\mathrm{H}$ structure is analyzed hereafter in this section. Figure $13(a)$ and $13(b)$ shows the mobility of sodium ions and water molecules respectively for varying $\mathrm{Si} / \mathrm{Al}$ ratios at a representative time of $8 \mathrm{~ns}$. In the case of sodium ions (as shown in Figure 13(a)), the mobility of sodium ions decreases with increase in Si/Al ratio which correlates well with the decreasing nature of diffusion coefficient in N-A-S-H with increasing Si/Al ratio as discussed earlier.

Due to the heterogeneity in the dynamics of water molecules in the $\mathrm{N}-\mathrm{A}-\mathrm{S}-\mathrm{H}$ structure, the water molecules diffuse with significantly different residence times in different regions. To distinguish between water molecules with different residence times, the self-part of Van Hove function is classified into mobile, $H_{M}(r, t)$, and immobile, $H_{I}(r, t)$ components:

$$
\begin{aligned}
& \left.H_{M}(r, t)=\frac{1}{N_{M}} \sum_{i}^{N_{M}}<\delta\left(r-\left|r_{i}(t+\tau)-r_{i}(\tau)\right|\right)\right\rangle \\
& \left.H_{I}(r, t)=\frac{1}{N_{I}} \sum_{i}^{N_{I}}<\delta\left(r-\left|r_{i}(t+\tau)-r_{i}(\tau)\right|\right)\right\rangle
\end{aligned}
$$

Where $N_{M}$ and $N_{M}$ are the number of mobile and immobile water molecules, respectively. The mobility of water molecules is classified as immobile and mobile water based on the MSD value as explained in the previous section. Figure 13(c) shows the mobile-immobile classification of the Van Hove correlation function at $t=6 \mathrm{~ns}$. The peak centered at 0.3-0.5 $\AA$ in $H(r, t)$ for immobile water in NASH3 corresponds to vibrational motion in a confined space in the disordered structure. The high intensity of the localized motion of immobile water molecules (Figure 13(c)) is related to the water molecules associated with the bridging $\mathrm{SiO}_{2}$ groups present in the system which effectively obstructs its diffusivity. On the other hand, mobile water displays superimposition of multiple peaks beyond $2 \AA$ which can be attributed to the hopping of water molecules in the network structure. In addition to forward hopping, some of the water molecules also show backward hopping which is identified by the presence of multiple hopping sites in their trajectories. Overall, the behavior observed in the figure described the anomalous and 
inhomogeneity of the confined water molecules in the structure. From Figures 13(b) and (c), it is noted that the dynamics of water molecules in the disordered N-A-S-H structure is not as distinct as observed in layered structure such as C-S- $\mathrm{H}^{60}$. As such, a clear composition-dependent trend is not observed in Figures 13(b) and (c). To shed more light on this, Figure 13(d) plots the probability of hopping of water molecules with varying Si/Al ratio. The probability of hopping of water molecules are computed by taking the area of the $H(r, t)$ curves are shown in Figure 13(b). The probability of hopping of water molecules decreases significantly with an increase in the Si/Al ratio. A $27 \%$ decrease in the probability of hopping is observed when the Si/Al ratio increases from 1 to 3 which is in line with the earlier observation on the diffusion of water molecules in $\mathrm{N}-\mathrm{A}-\mathrm{S}-\mathrm{H}$, shown earlier in Figure 10(b).
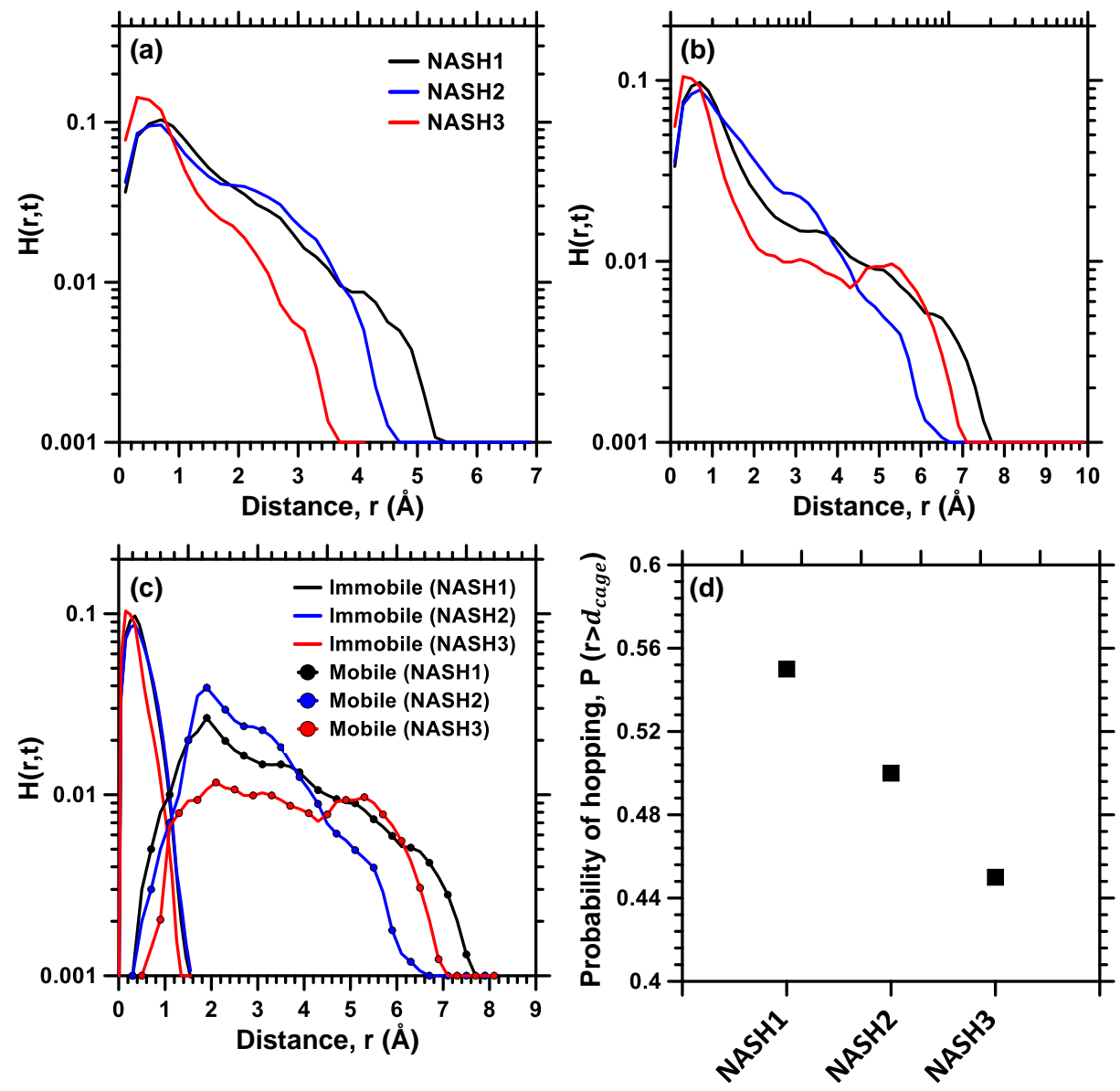

Figure 13: Self part Van Hove function for (a) sodium ions, (b) water molecules, and (c) immobile and mobile water, and (d) probability of hopping of water molecules in N-A-S-H for Si/Al $=1,2$ and 3 at $t=6$ ns.

\subsection{Influence of varying water content on the diffusion behavior of species in N-A-S-H structure}


This section focusses on the influence of varying water content on the diffusion behavior of sodium and water molecules in the NASH3 structure. A wide range of water content in N-A-S-H has been reported so far in the literature ${ }^{33-35,53}$. As such, the evaluation of realistic water content in N-A-S-H structure remains an open topic of research. In this study, four different water contents $(5,10,15$, and 20 wt\%) in the N-A$\mathrm{S}-\mathrm{H}$ structure are considered based on water contents reported in the literature ${ }^{33-35,53}$. Variations in water content is achieved by saving the configuration of the structure during GCMC at different intervals. It is noteworthy that the $\mathrm{N}-\mathrm{A}-\mathrm{S}-\mathrm{H}$ structure is saturated at water content equal to $20 \%$. The obtained structures were then equilibrated in NPT at 0 atm pressure and $300 \mathrm{~K}$ for $300 \mathrm{ps}$ and in NVT for $300 \mathrm{ps}$ followed by another $200 \mathrm{ps}$ for production. The validation of the molecular structures with different water contents based on the pair distribution function and structure factor are provided in section $\mathrm{C}$ of the supplementary document. Besides, the partial pair distribution functions of $\mathrm{Na}-\mathrm{O}, \mathrm{Na}-\mathrm{O} w, \mathrm{O}-\mathrm{O}, \mathrm{O}-\mathrm{Ow}$, $\mathrm{Ow}-\mathrm{Ow}, \mathrm{O}-\mathrm{H}$, and $\mathrm{Ow}-\mathrm{H}$ interactions with different water content are also detailed in section $\mathrm{D}$ of the supplementary document. It needs to be noted that partially saturated N-A-S-H structures are obtained from GCMC at various stages before equilibrium water content is reached and as such, the structures might not have been adequately equilibrated. However, the results still highlight various important information regarding the influence of water content on the diffusion of water molecules and alkali cation as explained hereafter.

\subsubsection{Nature of oxygen speciation in N-A-S-H with varying water content}

This sub-section evaluates the influence of water content on the oxygen speciation in N-A-S-H structure. Figure 14(a) shows the distribution of bridging oxygen (BO), non-bridging oxygen (NBO), and tri cluster oxygen (TO) in the system with varying water content. It is evident that BO decreases with an increase in water content and consequently the NBO increases. These results suggest significant de-polymerization of the structure with an increase in water content. A trace of TO is also observed in the structure. The presence of TO indicates the defect in the glass. Such presence of TO is also observed in the MD simulation of NAS glass ${ }^{93}$. Figure $14(\mathrm{~b})$ shows the fraction of $\mathrm{Si}-\mathrm{O}-\mathrm{Si}, \mathrm{Si}-\mathrm{O}-\mathrm{Al}$, and $\mathrm{Al}-\mathrm{O}-\mathrm{Al}$ in the $\mathrm{BO}$. It is observed that the majority of the network structure is formed by $\mathrm{Si}-\mathrm{O}-\mathrm{Si}$ and $\mathrm{Si}-\mathrm{O}-\mathrm{Al}$ bonds. 

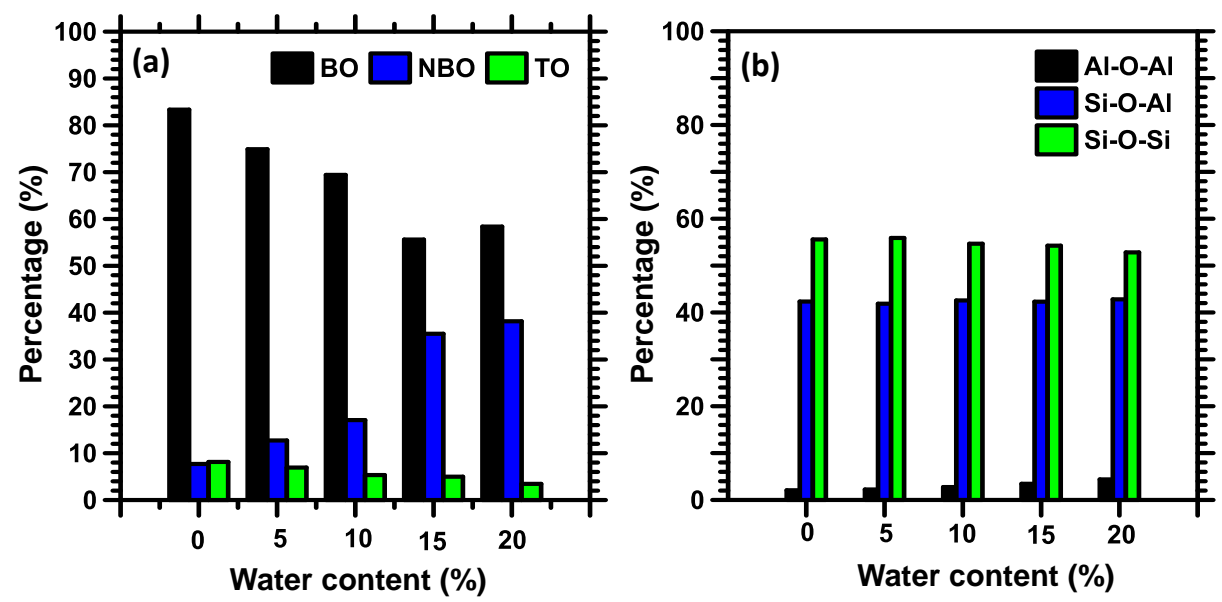

Figure 14: (a) Nature of oxygen speciation, and (b) fraction of BO components in NAS glass and NASH.

\subsection{4 $Q^{n}$ distribution and degree of de-polymerization in N-A-S-H with varying water content}

To quantify the effect of de-polymerization in the N-A-S-H structure with an increase in water content, the percentage of $Q^{n}$ distribution for N-A-S and N-A-S-H are compared in detail. The $Q^{n}$ distribution is based on the tetrahedral network formed by Si and $\mathrm{Al}$ ( $\mathrm{n}$ is the number of bridging oxygen) as shown in Figure 15(a-b).

Figure 15(a) presents the $Q^{n}$ distribution of $\mathrm{Si}$, which is consistent with the distribution reported in the literature ${ }^{34}$. It is found that with an increase in water content, the $Q^{4}$ decreases significantly whereas the $Q^{3}$ and $Q^{2}$ increase, which suggests de-polymerization in the structure with increasing water content.
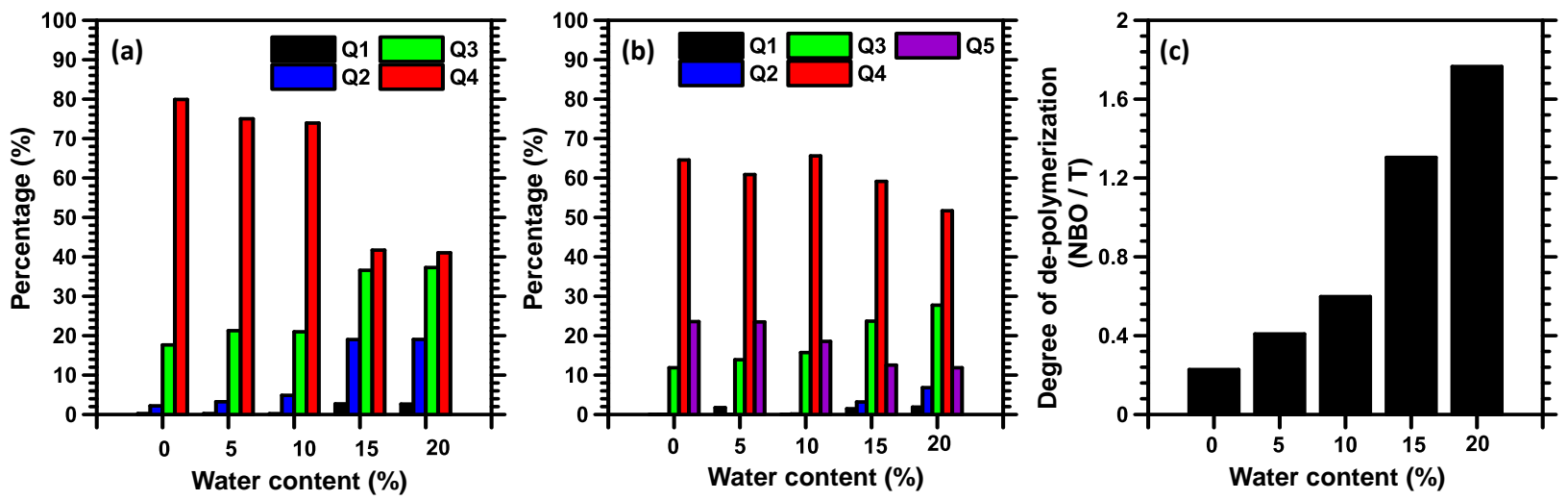

Figure 15: $Q^{n}$ analysis for (a) Si and (b) Al in NASH structure with different water content, and (c) degree of de-polymerization in the N-A-S and N-A-S-H structure.

Figure $15(\mathrm{~b})$ shows the $Q^{n}$ distribution of Al network. In such $Q^{n}$ distribution, 5-coordinated aluminum atoms with oxygen are observed (less than $20 \%$ ). Formation of such 5 -coordinated aluminum atoms with 
oxygen has also been reported for NAS and N-A-S-H structures in the literature ${ }^{34,93}$. However, with an increase in water content the $Q^{5}$ decreases. In the case of $\mathrm{Al}$, similar to the $Q^{n}$ distribution of $\mathrm{Si}, Q^{4}$ decreases and $Q^{3}$ increases with an increase in water content for the reasons explained earlier. It is observed that in the N-A-S-H gel, the water molecules help in stretching the Si-O-T (T = Si, Al) bonds which results in the separation between the tetrahedral $\mathrm{SiO}_{4}$ unit and nearby $\mathrm{AlO}_{4} / \mathrm{AlO}_{5}$ unit ${ }^{93}$.

Figure 15(c) quantifies the degree of de-polymerization in the N-A-S-H structure with respect to water content. The degree of de-polymerization, in this study, is measured as the ratio of the number of NBO with respect to the number of tetrahedral network $(T)$. As explained in various contexts earlier in this paper, the degree of depolymerization increases significantly with an increase in water content in N-A-S$\mathrm{H}$ due to the increased number of non-bridging oxygen (NBO) sites. The atomic structure of NASH3 showing the $Q^{n}$ network of $\mathrm{Si}$ and $\mathrm{Al}$ is shown in Figure 16.

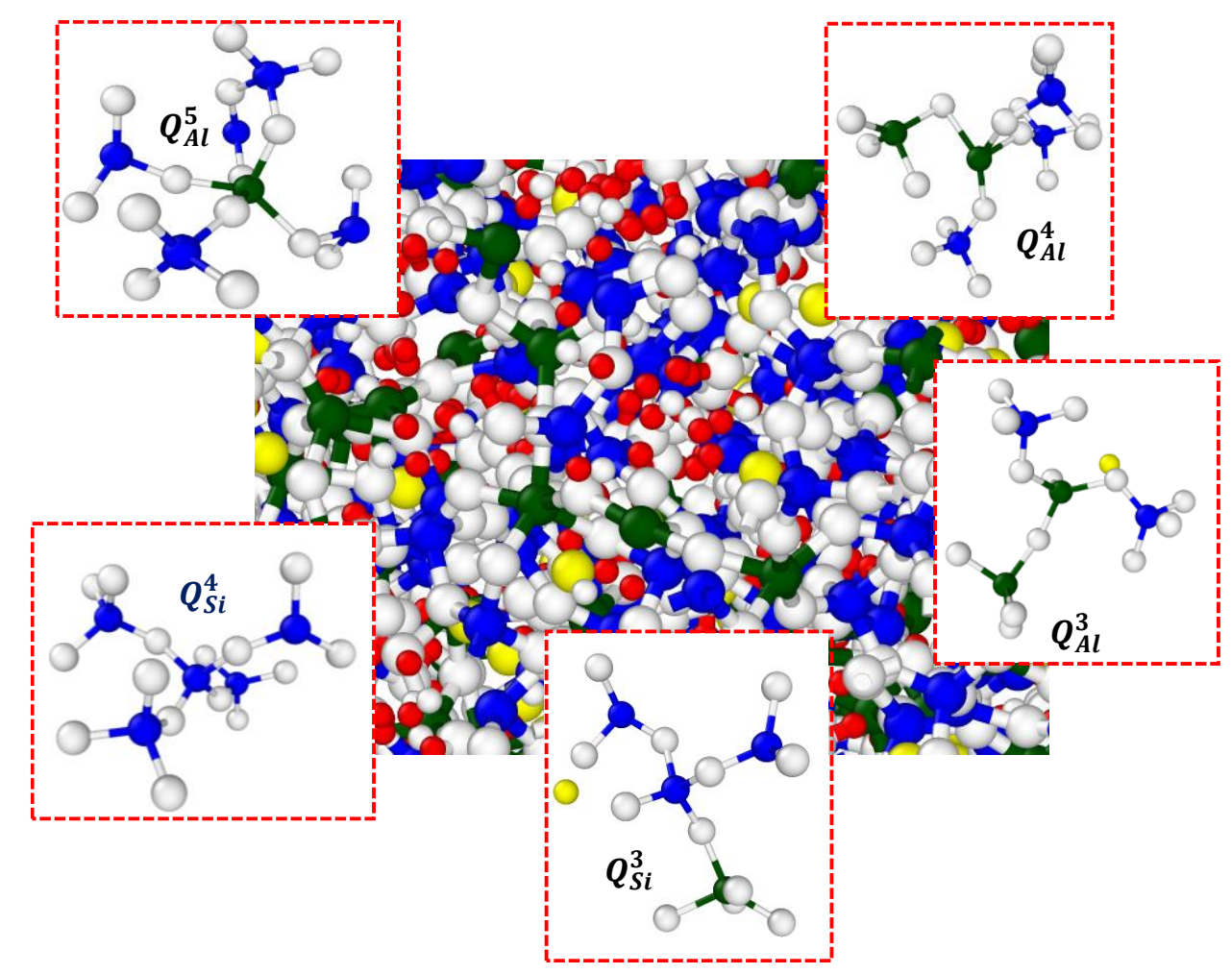

Figure 16: Atomic structure of NASH3 showing (a) $Q_{A l}^{5}$, (b) $Q_{A l}^{4}$, (c) $Q_{A l}^{3}$, (d) $Q_{S i}^{4}$ and (e) $Q_{S i}^{3}$ network. (Si: Navy blue, Al: Green, O: White and Na: Yellow).

\subsubsection{Diffusion coefficient of sodium and water molecules}

While the previous section showed the effect of water content on the network structure in N-A-S-H, this section quantifies the diffusion coefficient of sodium and confined water molecules based on Einstein's 
equation. Figure 17(a) shows the computed diffusion coefficient of sodium and the computed value increases with an increase of water content in the structure which can be attributed to the polarization field arising from water. Self-part Van Hove correlation for $\mathrm{Na}$ is also computed with respect to different water contents as shown in Figure 17(b) for $t=6$ ns which shows that The mobility of sodium ions increases with an increase in water content, similar to the trend observed in the influence of water content on the diffusion coefficient of $\mathrm{Na}$.
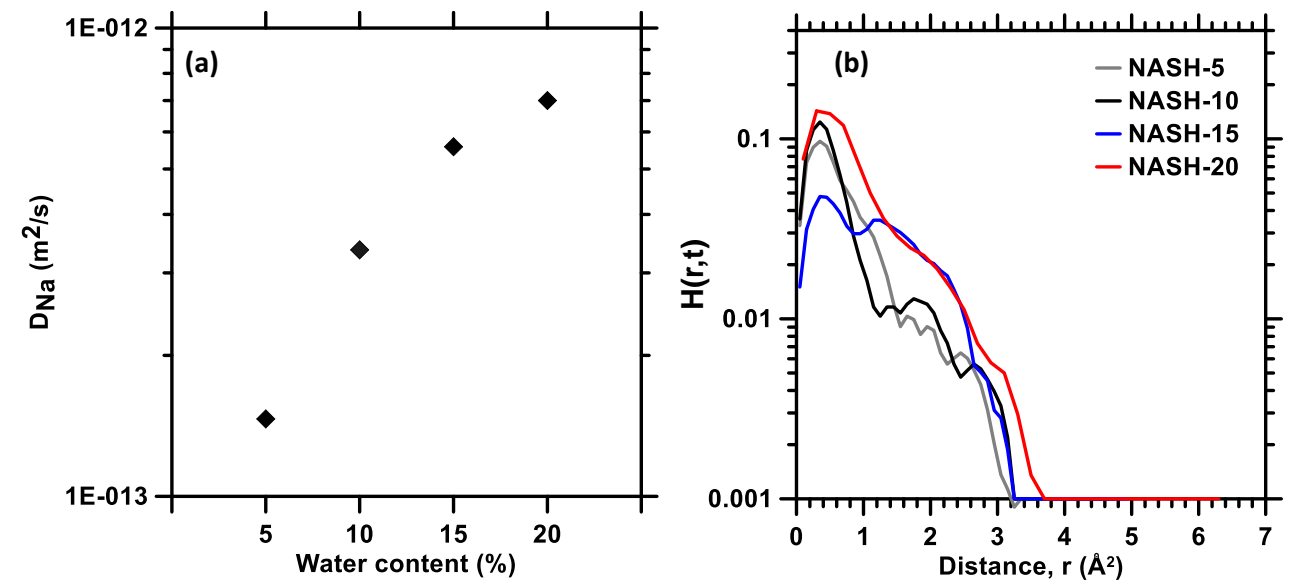

Figure 17: Plot for (a) diffusion coefficient, and (b) self-part Van Hove function for sodium ions with respect to different water content for $\mathrm{N}-\mathrm{A}-\mathrm{S}-\mathrm{H}$ (Si/AL equal to 3 ).

Figure 18(a) shows the ratio of the diffusion coefficient of water molecules in the disordered structure with respect to the diffusion coefficient of water bulk system $\left(D_{\text {bulk system }}=3.44 \times 10^{-9} \mathrm{~m}^{2} / \mathrm{s}\right)$. The computed values show an increasing trend with an increase in water content.
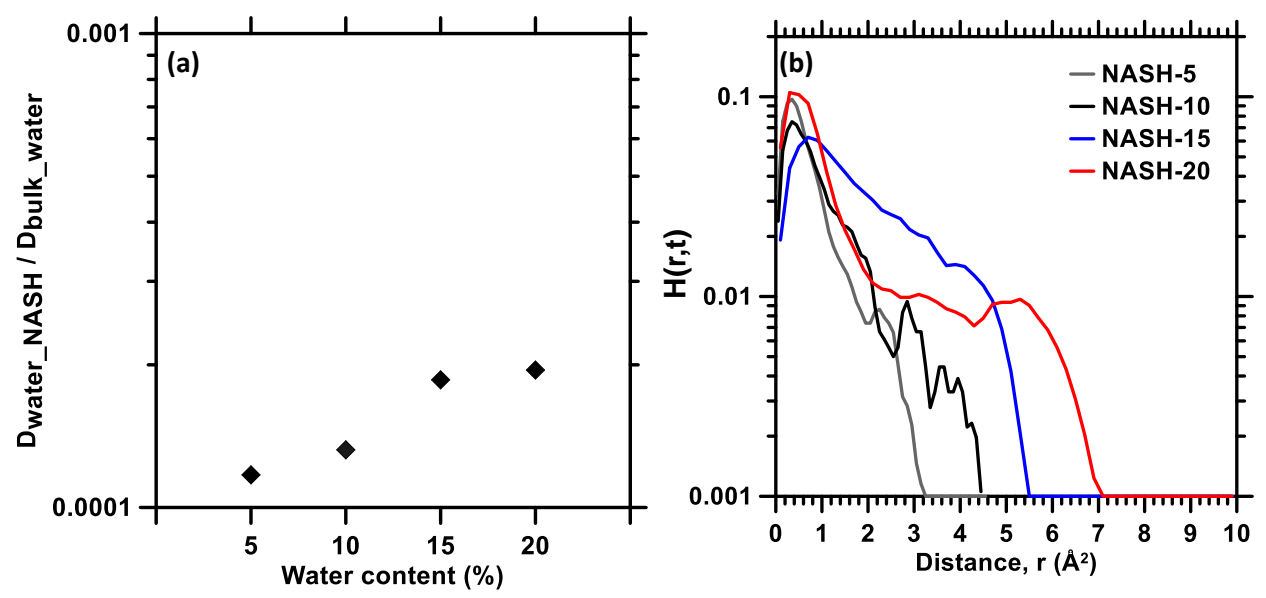

Figure 18: Plot for (a) ratio of diffusion of water molecules in N-A-S-H and that of water molecules in bulk water system, and (b) Self part Van Hove function for water molecules with different water content for $\mathrm{N}-\mathrm{A}-\mathrm{S}-\mathrm{H}$ with $\mathrm{Si} / \mathrm{AL}$ equal to 3 . The water content in $\mathrm{N}-\mathrm{A}-\mathrm{S}-\mathrm{H}$ (Si/Al equal to 3 ) is fully saturated for the case when water content equal to $20 \%$. 
To shed more light on the mobility of water molecules in a confined structure with respect to different water contents, self-part Van Hove Correlation for different water contents is plotted as shown in Figure 18(b). The general trend in Figure 18(b) suggests a progressive increase in mobility of water molecules with increasing water content which is in line with the observations of the diffusion coefficient for water molecules shown in Figure 18(a). A few irregularities (multiple local peaks) are observed for the water content below $15 \%$ which can be attributed to the significantly lower degree of depolymerization in those structures which may have prevented the water molecules to diffuse easily.

\section{CONCLUSION}

This study evaluates the dynamics of confined water and its interplay with alkali cation (sodium) in sodium aluminosilicate hydrate (N-A-S-H) gel formed via alkaline activation of fly ash. To evaluate the influence of the composition of N-A-S-H on the water dynamics as well as the diffusion behavior of sodium, three different N-A-S-H compositions are considered with Si/Al ratio ranging from 1 to 3 . Evaluation of water dynamics in N-A-S-H reveals four stages, namely ballistic, caged, transition, and diffusive regimes, similar to $\mathrm{C}-\mathrm{S}-\mathrm{H}$. However, due to the disordered structure of N-A-S-H compared to the layered structure in C-S$\mathrm{H}$, the anomalous behavior of water in the confined space is prevalent in N-A-S-H. This can be observed from the individual movement of water molecules in the system. Evaluation of composition-dependent diffusion behavior revealed that the diffusion coefficient of water molecules and sodium decreases significantly with an increase in Si/Al ratio which can be attributed to the increase in the fraction of small ring size (2-4 size rings) with increasing Si/Al ratio that restricts the mobility of species within N-A-S-H. Detailed evaluation of MSD and Van Hove space-time correlation function showed the heterogeneity of the water molecules in the N-A-S-H structure. While C-S-H shows a clear composition-dependent trend of Van Hove space-time correlation function due to the presence of water at the interlayer spaces of C-S-H, no clear composition-dependent trend was observed in disordered $\mathrm{N}-\mathrm{A}-\mathrm{S}-\mathrm{H}$ structure where water molecules are randomly distributed within the structure. To get more insights on the dynamics of confined water in N-A-S-H, the water molecules are categorized into mobile and immobile water by tracking their MSDs and trajectories and the probability of hopping of water molecules with varying Si/Al ratio was computed from the Van Hove correlation function. The probability of hopping of water molecules decreased significantly with an increase in Si/Al ratio which is in line with the earlier trends of diffusion coefficients. Over the whole range of Si/Al ratio, the diffusivity of water molecules in N-A-S-H is lower than that of $\mathrm{C}-\mathrm{S}-\mathrm{H}$. This is attributed to the disordered structure of the $\mathrm{N}-\mathrm{A}-\mathrm{S}-\mathrm{H}$ compared to the layered structure of C-S-H. 
To further evaluate the effect of water content in the N-A-S-H structure, four different contents are demonstrated ( $5 \%, 10 \%, 15 \%$, and $20 \%$ water content). It is observed that the mobility of sodium increases with an increase in water content, which is also observed macroscopically when geopolymer is exposed to water-soluble salts. Due to the dissociation of water, which is the salient feature of ReaxFF (developed somewhere else) to model the chemical reaction, the $\mathrm{Si}-\mathrm{O}-\mathrm{Na}$ network is converted to $\mathrm{Si}-\mathrm{O}-\mathrm{H}$ and $\mathrm{Na}-$ $\mathrm{OH}$ which explains the alkali-leaching issue in fly ash-based geopolymers observed macroscopically. In addition, the effect of the network connectivity with an increase in water content is also presented which is computed from the number of bridging oxygen (BO), non-bridging oxygen (NBO), and $Q^{n}$ distribution (in particular $Q^{4}$ ) of Si and Al network present in the structure. The results show a significant decrease in $Q^{4}$ with increasing water content which clearly indicates the de-polymerization in the structure due to the combined effect of dynamics of confined water and its interaction with alkali cation in N-A-S-H structure. Overall, this study demonstrates the nature of confined water in the polyhedral network of aluminosilicates in N-A-S-H gel and the effect of alkali ions with varying Si/Al ratio as well as varying water content. This will further help in understanding the fundamental mechanisms that control the chemomechanical stability of the geopolymer structure which can serve as a starting point toward multiscale simulation-based design of durable geopolymers.

\section{REFERENCES}

(1) Fernández-Jiménez, A.; Palomo, A. Composition and Microstructure of Alkali Activated Fly Ash Binder: Effect of the Activator. Cement and Concrete Research 2005, 35 (10), 1984-1992.

(2) Rashad, A. M. Alkali-Activated Metakaolin: A Short Guide for Civil Engineer-an Overview. Construction and Building Materials 2013, 41, 751-765.

(3) Ravikumar, D.; Peethamparan, S.; Neithalath, N. Structure and Strength of $\mathrm{NaOH}$ Activated Concretes Containing Fly Ash or GGBFS as the Sole Binder. Cement and Concrete Composites 2010, 32 (6), 399-410.

(4) Yang, K.-H.; Song, J.-K.; Ashour, A. F.; Lee, E.-T. Properties of Cementless Mortars Activated by Sodium Silicate. Construction and Building Materials 2008, 22 (9), 1981-1989.

(5) Puertas, F.; Martínez-Ramírez, S.; Alonso, S.; Vazquez, T. Alkali-Activated Fly Ash/Slag Cements: Strength Behaviour and Hydration Products. Cement and Concrete Research 2000, 30 (10), 16251632.

(6) Das, S.; Yang, P.; Singh, S. S.; Mertens, J. C. E.; Xiao, X.; Chawla, N.; Neithalath, N. Effective Properties of a Fly Ash Geopolymer: Synergistic Application of X-Ray Synchrotron Tomography, Nanoindentation, and Homogenization Models. Cement and Concrete Research 2015, 78, 252-262.

(7) Provis, J. L.; Palomo, A.; Shi, C. Advances in Understanding Alkali-Activated Materials. Cement and Concrete Research 2015, 78, 110-125. 
(8) Shi, C. Alkali-Activated Cements and Concretes, 1st ed.; CRC Press, 2003.

(9) Provis, J. L.; Deventer, J. S. J. van. Alkali Activated Materials: State-of-the-Art Report, RILEM TC 224AAM; Springer Science \& Business Media, 2013.

(10) Yang, T.; Yao, X.; Zhang, Z.; Wang, H. Mechanical Property and Structure of Alkali-Activated Fly Ash and Slag Blends. Journal of Sustainable Cement-Based Materials 2012, 1 (4), 167-178.

(11) Cassagnabère, F.; Mouret, M.; Escadeillas, G.; Broilliard, P.; Bertrand, A. Metakaolin, a Solution for the Precast Industry to Limit the Clinker Content in Concrete: Mechanical Aspects. Construction and Building Materials 2010, 24 (7), 1109-1118.

(12) Thomas, R. J.; Peethamparan, S. Alkali-Activated Concrete: Engineering Properties and StressStrain Behavior. Construction and Building Materials 2015, 93, 49-56.

(13) Nayak, S.; Kizilkanat, A.; Neithalath, N.; Das, S. Experimental and Numerical Investigation of the Fracture Behavior of Particle Reinforced Alkali Activated Slag Mortars. Journal of Materials in Civil Engineering 2019, 31 (5), 04019043.

(14) McLellan, B. C.; Williams, R. P.; Lay, J.; van Riessen, A.; Corder, G. D. Costs and Carbon Emissions for Geopolymer Pastes in Comparison to Ordinary Portland Cement. Journal of Cleaner Production 2011, 19 (9-10), 1080-1090.

(15) Provis, J. L.; Bernal, S. A. Geopolymers and Related Alkali-Activated Materials. Annual Review of Materials Research 2014, 44 (1), 299-327.

(16) Duxson, P.; Fernández-Jiménez, A.; Provis, J. L.; Lukey, G. C.; Palomo, A.; van Deventer, J. S. J. Geopolymer Technology: The Current State of the Art. J Mater Sci 2007, 42 (9), 2917-2933.

(17) Ly, L.; Vance, E. R.; Perera, D. S.; Aly, Z.; Olufson, K. Leaching of Geopolymers in Deionised Water. Advances in Technology of Materials and Materials Processing Journal 2006, 8 (2), 236-247.

(18) Najafi Kani, E.; Allahverdi, A.; Provis, J. L. Efflorescence Control in Geopolymer Binders Based on Natural Pozzolan. Cement and Concrete Composites 2012, 34 (1), 25-33.

(19) Škvára, F.; Kopecký, L.; Šmilauer, V.; Bittnar, Z. Material and Structural Characterization of Alkali Activated Low-Calcium Brown Coal Fly Ash. Journal of Hazardous Materials 2009, 168 (2-3), 711720.

(20) Škvára, F.; Kopeckỳ, L.; Myšková, L.; Šmilauer, V.; Alberovska, L.; Vinšová, L. Aluminosilicate Polymers-Influence of Elevated Temperatures, Efflorescence. Ceramics-Silikáty 2009, 53 (4), 276282.

(21) Škvára, F.; Šmilauer, V.; Hlaváček, P.; Kopeckỳ, L.; Cilova, Z. A Weak Alkali Bond in (N, K)-A-S-H Gels: Evidence from Leaching and Modeling. Ceramics-Silikáty 2012, 56 (4), 374-382.

(22) Zhang, Z.; Provis, J. L.; Ma, X.; Reid, A.; Wang, H. Efflorescence and Subflorescence Induced Microstructural and Mechanical Evolution in Fly Ash-Based Geopolymers. Cement and Concrete Composites 2018, 92, 165-177. https://doi.org/10.1016/j.cemconcomp.2018.06.010.

(23) Temuujin, J.; Minjigmaa, A.; Lee, M.; Chen-Tan, N.; van Riessen, A. Characterisation of Class F Fly Ash Geopolymer Pastes Immersed in Acid and Alkaline Solutions. Cement and Concrete Composites 2011, 33 (10), 1086-1091. https://doi.org/10.1016/j.cemconcomp.2011.08.008. 
(24) Najafi Kani, E.; Allahverdi, A.; Provis, J. L. Efflorescence Control in Geopolymer Binders Based on Natural Pozzolan. Cement and Concrete Composites 2012, 34 (1), 25-33. https://doi.org/10.1016/j.cemconcomp.2011.07.007.

(25) Bernal, S. A.; de Gutiérrez, R. M.; Provis, J. L. Engineering and Durability Properties of Concretes Based on Alkali-Activated Granulated Blast Furnace Slag/Metakaolin Blends. Construction and Building Materials 2012, 33, 99-108.

(26) Burciaga-Díaz, O.; Escalante-García, J. I.; Arellano-Aguilar, R.; Gorokhovsky, A. Statistical Analysis of Strength Development as a Function of Various Parameters on Activated Metakaolin/Slag Cements. Journal of the American Ceramic Society 2010, 93 (2), 541-547. https://doi.org/10.1111/j.1551-2916.2009.03414.x.

(27) Zhang, Z.; Provis, J. L.; Reid, A.; Wang, H. Fly Ash-Based Geopolymers: The Relationship between Composition, Pore Structure and Efflorescence. Cement and Concrete Research 2014, 64, 30-41. https://doi.org/10.1016/j.cemconres.2014.06.004.

(28) van Duin, A. C. T.; Dasgupta, S.; Lorant, F.; Goddard, W. A. ReaxFF: A Reactive Force Field for Hydrocarbons. J. Phys. Chem. A 2001, 105 (41), 9396-9409.

(29) Bakharev, T. Geopolymeric Materials Prepared Using Class F Fly Ash and Elevated Temperature Curing. Cement and Concrete Research 2005, 35 (6), 1224-1232.

(30) Drexler, K. E.; Peterson, C.; Pergamit, G. Unbounding the Future: The Nanotechnology Revolution. In William Morrow; New York, 1991.

(31) Sadat, M. R.; Bringuier, S.; Muralidharan, K.; Runge, K.; Asaduzzaman, A.; Zhang, L. An Atomistic Characterization of the Interplay between Composition, Structure and Mechanical Properties of Amorphous Geopolymer Binders. Journal of Non-Crystalline Solids 2016, 434, 53-61.

(32) Sadat, M. R.; Bringuier, S.; Muralidharan, K.; Frantziskonis, G.; Zhang, L. Atomic-Scale Dynamics and Mechanical Response of Geopolymer Binder under Nanoindentation. Computational Materials Science 2018, 142, 227-236.

(33) Sadat, M. R.; Bringuier, S.; Asaduzzaman, A.; Muralidharan, K.; Zhang, L. A Molecular Dynamics Study of the Role of Molecular Water on the Structure and Mechanics of Amorphous Geopolymer Binders. J. Chem. Phys. 2016, 145 (13), 134706.

(34) Hou, D.; Zhang, Y.; Yang, T.; Zhang, J.; Pei, H.; Zhang, J.; Jiang, J.; Li, T. Molecular Structure, Dynamics, and Mechanical Behavior of Sodium Aluminosilicate Hydrate (NASH) Gel at Elevated Temperature: A Molecular Dynamics Study. Physical Chemistry Chemical Physics 2018, 20 (31), 20695-20711.

(35) Lolli, F.; Manzano, H.; Provis, J. L.; Bignozzi, M. C.; Masoero, E. Atomistic Simulations of Geopolymer Models: The Impact of Disorder on Structure and Mechanics. ACS Appl. Mater. Interfaces 2018, 10 (26), 22809-22820.

(36) Duxson, P.; Provis, J. L.; Lukey, G. C.; Separovic, F.; van Deventer, J. S. J. 29Si NMR Study of Structural Ordering in Aluminosilicate Geopolymer Gels. Langmuir 2005, 21 (7), 3028-3036.

(37) White, C. E.; Provis, J. L.; Proffen, T.; Van Deventer, J. S. J. The Effects of Temperature on the Local Structure of Metakaolin-Based Geopolymer Binder: A Neutron Pair Distribution Function Investigation: The Effects of Temperature on the Local Structure of Metakaolin-Based Geopolymer Binder. Journal of the American Ceramic Society 2010, 93 (10), 3486-3492. 
(38) White, C. E.; Provis, J. L.; Llobet, A.; Proffen, T.; van Deventer, J. S. J. Evolution of Local Structure in Geopolymer Gels: An In Situ Neutron Pair Distribution Function Analysis: Evolution of Local Structure in Geopolymer Gels. Journal of the American Ceramic Society 2011, 94 (10), 3532-3539.

(39) White, C. E.; Page, K.; Henson, N. J.; Provis, J. L. In Situ Synchrotron X-Ray Pair Distribution Function Analysis of the Early Stages of Gel Formation in Metakaolin-Based Geopolymers. Applied Clay Science 2013, 73, 17-25.

(40) White, C. E.; Provis, J. L.; Bloomer, B.; Henson, N. J.; Page, K. In Situ X-Ray Pair Distribution Function Analysis of Geopolymer Gel Nanostructure Formation Kinetics. Physical Chemistry Chemical Physics 2013, 15 (22), 8573.

(41) Singh, P. S.; Trigg, M.; Burgar, I.; Bastow, T. Geopolymer Formation Processes at Room Temperature Studied by 29Si and 27AI MAS-NMR. Materials Science and Engineering: A 2005, 396 (1), 392-402.

(42) Barbosa, V. F. F.; MacKenzie, K. J. D.; Thaumaturgo, C. Synthesis and Characterisation of Materials Based on Inorganic Polymers of Alumina and Silica: Sodium Polysialate Polymers. International Journal of Inorganic Materials 2000, 2 (4), 309-317.

(43) Duxson, P.; Lukey, G. C.; Separovic, F.; van Deventer, J. S. J. Effect of Alkali Cations on Aluminum Incorporation in Geopolymeric Gels. Ind. Eng. Chem. Res. 2005, 44 (4), 832-839.

(44) Rahier, H.; Van Mele, B.; Biesemans, M.; Wastiels, J.; Wu, X. Low-Temperature Synthesized Aluminosilicate Glasses: Part I Low-Temperature Reaction Stoichiometry and Structure of a Model Compound. JOURNAL OF MATERIALS SCIENCE 1996, 31 (1), 71-79.

(45) Provis, J. L.; Lukey, G. C.; van Deventer, J. S. J. Do Geopolymers Actually Contain Nanocrystalline Zeolites? A Reexamination of Existing Results. Chem. Mater. 2005, 17 (12), 3075-3085.

(46) Wang, M.; Wang, B.; Krishnan, N. M. A.; Yu, Y.; Smedskjaer, M. M.; Mauro, J. C.; Sant, G.; Bauchy, M. Ion Exchange Strengthening and Thermal Expansion of Glasses: Common Origin and Critical Role of Network Connectivity. Journal of Non-Crystalline Solids 2017, 455, 70-74.

(47) Li, X.; Song, W.; Yang, K.; Krishnan, N. M. A.; Wang, B.; Smedskjaer, M. M.; Mauro, J. C.; Sant, G.; Balonis, M.; Bauchy, M. Cooling Rate Effects in Sodium Silicate Glasses: Bridging the Gap between Molecular Dynamics Simulations and Experiments. J. Chem. Phys. 2017, 147 (7), 074501. https://doi.org/10.1063/1.4998611.

(48) Puibasset, J.; Pellenq, R. J.-M. Grand Canonical Monte Carlo Simulation Study of Water Adsorption in Silicalite at 300 K. The Journal of Physical Chemistry B 2008, 112 (20), 6390-6397.

(49) Hoover, W. G. Canonical Dynamics: Equilibrium Phase-Space Distributions. Phys. Rev. A 1985, 31 (3), 1695-1697.

(50) Bauchy, M. Structural, Vibrational, and Elastic Properties of a Calcium Aluminosilicate Glass from Molecular Dynamics Simulations: The Role of the Potential. The Journal of Chemical Physics 2014, $141(2), 024507$.

(51) Yu, Y.; Wang, B.; Wang, M.; Sant, G.; Bauchy, M. Reactive Molecular Dynamics Simulations of Sodium Silicate Glasses - Toward an Improved Understanding of the Structure. International Journal of Applied Glass Science 2017, 8 (3), 276-284. 
(52) Pedone, A.; Malavasi, G.; Cormack, A. N.; Segre, U.; Menziani, M. C. Insight into Elastic Properties of Binary Alkali Silicate Glasses; Prediction and Interpretation through Atomistic Simulation Techniques. Chem. Mater. 2007, 19 (13), 3144-3154.

(53) Lizcano, M.; Gonzalez, A.; Basu, S.; Lozano, K.; Radovic, M. Effects of Water Content and Chemical Composition on Structural Properties of Alkaline Activated Metakaolin-Based Geopolymers. Journal of the American Ceramic Society 2012, 95 (7), 2169-2177.

(54) Šmilauer, V.; Hlaváček, P.; Škvára, F.; Šulc, R.; Kopecký, L.; Němeček, J. Micromechanical Multiscale Model for Alkali Activation of Fly Ash and Metakaolin. J Mater Sci 2011, 46 (20), 6545-6555. https://doi.org/10.1007/s10853-011-5601-x.

(55) Duxson, P.; Lukey, G. C.; van Deventer, J. S. J. Physical Evolution of Na-Geopolymer Derived from Metakaolin up to $1000^{\circ} \mathrm{C}$. Journal of Materials Science 2007, 42 (9), 3044-3054.

(56) Lyngdoh, G. A.; Kumar, R.; Krishnan, N. M. A.; Das, S. Realistic Atomic Structure of Fly Ash-Based Geopolymer Gels: Insights from Molecular Dynamics Simulations. J. Chem. Phys. 2019, 151 (6), 064307.

(57) Plimpton, S. Fast Parallel Algorithms for Short-Range Molecular Dynamics. Journal of Computational Physics 1995, 117 (1), 1-19.

(58) Stukowski, A. Visualization and Analysis of Atomistic Simulation Data with OVITO-the Open Visualization Tool. Modelling Simul. Mater. Sci. Eng. 2009, 18 (1), 015012. https://doi.org/10.1088/0965-0393/18/1/015012.

(59) Klenk, M. J.; Lai, W. Finite-Size Effects on the Molecular Dynamics Simulation of Fast-lon Conductors: A Case Study of Lithium Garnet Oxide Li7La3Zr2012. Solid State Ionics 2016, 289, 143149. https://doi.org/10.1016/j.ssi.2016.03.002.

(60) Qomi, M. J. A.; Bauchy, M.; Ulm, F.-J.; Pellenq, R. J.-M. Anomalous Composition-Dependent Dynamics of Nanoconfined Water in the Interlayer of Disordered Calcium-Silicates. The Journal of Chemical Physics 2014, 140 (5), 054515.

(61) Senftle, T. P.; Hong, S.; Islam, M. M.; Kylasa, S. B.; Zheng, Y.; Shin, Y. K.; Junkermeier, C.; EngelHerbert, R.; Janik, M. J.; Aktulga, H. M.; Verstraelen, T.; Grama, A.; Duin, A. C. T. van. The ReaxFF Reactive Force-Field: Development, Applications and Future Directions. npj Comput Mater 2016, 2 (1), 1-14. https://doi.org/10.1038/npjcompumats.2015.11.

(62) van Duin, A. C. T.; Strachan, A.; Stewman, S.; Zhang, Q.; Xu, X.; Goddard, W. A. ReaxFFSiO Reactive Force Field for Silicon and Silicon Oxide Systems. J. Phys. Chem. A 2003, 107 (19), 3803-3811.

(63) Zhang, Y.; Wang, X.; Li, Q.; Yang, R.; Li, C. A ReaxFF Molecular Dynamics Study of the Pyrolysis Mechanism of Oleic-Type Triglycerides. Energy Fuels 2015, 29 (8), 5056-5068.

(64) Bauchy, M.; Laubie, H.; Abdolhosseini Qomi, M. J.; Hoover, C. G.; Ulm, F.-J.; Pellenq, R. J.-M. Fracture Toughness of Calcium-Silicate-Hydrate from Molecular Dynamics Simulations. Journal of Non-Crystalline Solids 2015, 419, 58-64.

(65) Pitman, M. C.; van Duin, A. C. T. Dynamics of Confined Reactive Water in Smectite Clay-Zeolite Composites. J. Am. Chem. Soc. 2012, 134 (6), 3042-3053. https://doi.org/10.1021/ja208894m. 
(66) Krishnan, N. M. A.; Wang, B.; Le Pape, Y.; Sant, G.; Bauchy, M. Irradiation-Driven Amorphous-toGlassy Transition in Quartz: The Crucial Role of the Medium-Range Order in Crystallization. Physical Review Materials 2017, 1 (5).

(67) Krishnan, N. M. A.; Ravinder, R.; Kumar, R.; Le Pape, Y.; Sant, G.; Bauchy, M. Density-Stiffness Scaling in Minerals upon Disordering: Irradiation vs. Vitrification. Acta Materialia 2019, 166, 611617.

(68) Wright, A. C. The Comparison of Molecular Dynamics Simulations with Diffraction Experiments. Journal of Non-Crystalline Solids 1993, 159 (3), 264-268.

(69) Wright, A. C. Neutron and X-Ray Amorphography. Journal of Non-Crystalline Solids 1988, 106 (13), 1-16. https://doi.org/10.1016/0022-3093(88)90218-9.

(70) Du, J.; Corrales, L. R. Compositional Dependence of the First Sharp Diffraction Peaks in Alkali Silicate Glasses: A Molecular Dynamics Study. Journal of Non-Crystalline Solids 2006, 352 (30-31), 32553269. https://doi.org/10.1016/j.jnoncrysol.2006.05.025.

(71) Provis, J. L.; Hajimohammadi, A.; White, C. E.; Bernal, S. A.; Myers, R. J.; Winarski, R. P.; Rose, V.; Proffen, T. E.; Llobet, A.; van Deventer, J. S. J. Nanostructural Characterization of Geopolymers by Advanced Beamline Techniques. Cement and Concrete Composites 2013, 36, 56-64. https://doi.org/10.1016/j.cemconcomp.2012.07.003.

(72) Hahn, S. H.; Rimsza, J.; Criscenti, L.; Sun, W.; Deng, L.; Du, J.; Liang, T.; Sinnott, S. B.; van Duin, A. C. T. Development of a ReaxFF Reactive Force Field for NaSiOx/Water Systems and Its Application to Sodium and Proton Self-Diffusion. J. Phys. Chem. C 2018, 122 (34), 19613-19624.

(73) Skipper, N. T.; Neilson, G. W. X-Ray and Neutron Diffraction Studies on Concentrated Aqueous Solutions of Sodium Nitrate and Silver Nitrate. J. Phys.: Condens. Matter 1989, 1 (26), 4141-4154.

(74) Howe, M. A. The Hydration of Ions in Aqueous Solution: Reverse Monte Carlo Analysis of Neutron Diffraction Data. J. Phys.: Condens. Matter 1990, 2 (3), 741-748.

(75) Impey, R. W.; Madden, P. A.; McDonald, I. R. Hydration and Mobility of lons in Solution. J. Phys. Chem. 1983, 87 (25), 5071-5083.

(76) Ohkubo, T.; Gin, S.; Collin, M.; Iwadate, Y. Molecular Dynamics Simulation of Water Confinement in Disordered Aluminosilicate Subnanopores. Scientific Reports 2018, 8 (1).

(77) Venkatnathan, A.; Devanathan, R.; Dupuis, M. Atomistic Simulations of Hydrated Nafion and Temperature Effects on Hydronium Ion Mobility. J. Phys. Chem. B 2007, 111 (25), 7234-7244. https://doi.org/10.1021/jp0700276.

(78) Cui, S.; Liu, J.; Selvan, M. E.; Keffer, D. J.; Edwards, B. J.; Steele, W. V. A Molecular Dynamics Study of a Nafion Polyelectrolyte Membrane and the Aqueous Phase Structure for Proton Transport. J. Phys. Chem. B 2007, 111 (9), 2208-2218.

(79) Urata, S.; Irisawa, J.; Takada, A.; Shinoda, W.; Tsuzuki, S.; Mikami, M. Molecular Dynamics Simulation of Swollen Membrane of Perfluorinated lonomer. J. Phys. Chem. B 2005, 109 (9), 42694278.

(80) Chen, M.; Ko, H.-Y.; Remsing, R. C.; Andrade, M. F. C.; Santra, B.; Sun, Z.; Selloni, A.; Car, R.; Klein, M. L.; Perdew, J. P.; Wu, X. Ab Initio Theory and Modeling of Water. PNAS 2017, 114 (41), 1084610851. 
(81) Raju, M.; Kim, S.-Y.; van Duin, A. C. T.; Fichthorn, K. A. ReaxFF Reactive Force Field Study of the Dissociation of Water on Titania Surfaces. J. Phys. Chem. C 2013, 117 (20), 10558-10572.

(82) Krishnan, N. M. A.; Wang, B.; Falzone, G.; Le Pape, Y.; Neithalath, N.; Pilon, L.; Bauchy, M.; Sant, G. Confined Water in Layered Silicates: The Origin of Anomalous Thermal Expansion Behavior in Calcium-Silicate-Hydrates. ACS Applied Materials \& Interfaces 2016, 8 (51), 35621-35627. https://doi.org/10.1021/acsami.6b11587.

(83) Hahn, S. H.; van Duin, A. C. T. Surface Reactivity and Leaching of a Sodium Silicate Glass under an Aqueous Environment: A ReaxFF Molecular Dynamics Study. J. Phys. Chem. C 2019, 123 (25), 15606-15617.

(84) Krishnan, N. M. A.; Wang, B.; Sant, G.; Phillips, J. C.; Bauchy, M. Revealing the Effect of Irradiation on Cement Hydrates: Evidence of a Topological Self-Organization. ACS Applied Materials \& Interfaces 2017, 9 (37), 32377-32385. https://doi.org/10.1021/acsami.7b09405.

(85) Soper, A. K. The Radial Distribution Functions of Water and Ice from 220 to $673 \mathrm{~K}$ and at Pressures up to 400 MPa. Chemical Physics 2000, 258 (2), 121-137.

(86) Smedskjaer, M. M.; Zheng, Q.; Mauro, J. C.; Potuzak, M.; Mørup, S.; Yue, Y. Sodium Diffusion in Boroaluminosilicate Glasses. Journal of Non-Crystalline Solids 2011, 357 (22-23), 3744-3750.

(87) Le Roux, S.; Jund, P. Ring Statistics Analysis of Topological Networks: New Approach and Application to Amorphous GeS2 and SiO2 Systems. Computational Materials Science 2010, 49 (1), 70-83.

(88) Lloyd, R. R.; Provis, J. L.; van Deventer, J. S. J. Pore Solution Composition and Alkali Diffusion in Inorganic Polymer Cement. Cement and Concrete Research 2010, 40 (9), 1386-1392.

(89) Bauchy, M.; Micoulaut, M. From Pockets to Channels: Density-Controlled Diffusion in Sodium Silicates. Phys. Rev. B 2011, 83 (18), 184118.

(90) Zhang, Y.; Ni, H.; Chen, Y. Diffusion Data in Silicate Melts. Reviews in Mineralogy and Geochemistry 2010, 72 (1), 311-408. https://doi.org/10.2138/rmg.2010.72.8.

(91) Teixeira, J.; Bellissent-Funel, M.-C.; Chen, S. H.; Dianoux, A. J. Experimental Determination of the Nature of Diffusive Motions of Water Molecules at Low Temperatures. Phys. Rev. A 1985, 31 (3), 1913-1917. https://doi.org/10.1103/PhysRevA.31.1913.

(92) Chen, S.-H.; Gallo, P.; Bellissent-Funel, M.-C. Slow Dynamics of Interfacial Water. Can. J. Phys. 1995, 73 (11-12), 703-709. https://doi.org/10.1139/p95-104.

(93) Xiang, Y.; Du, J.; Smedskjaer, M. M.; Mauro, J. C. Structure and Properties of Sodium Aluminosilicate Glasses from Molecular Dynamics Simulations. The Journal of Chemical Physics 2013, 139 (4), 044507. 